\title{
Mirror Symmetry Breaking in Liquids and Their Impact on the Development of Homochirality in Abiogenesis: Emerging Proto-RNA as Source of Biochirality?
}

\author{
Carsten Tschierske *(1) and Christian Dressel \\ Martin Luther University Halle-Wittenberg, Institute of Chemistry, Kurt-Mothes Str. 2, 06120 Halle, Germany; \\ dresselchristian@gmx.de \\ * Correspondence: carsten.tschierske@chemie.uni-halle.de
}

Received: 30 May 2020; Accepted: 15 June 2020; Published: 2 July 2020

check for updates

\begin{abstract}
Recent progress in mirror symmetry breaking and chirality amplification in isotropic liquids and liquid crystalline cubic phases of achiral molecule is reviewed and discussed with respect to its implications for the hypothesis of emergence of biological chirality. It is shown that mirror symmetry breaking takes place in fluid systems where homochiral interactions are preferred over heterochiral and a dynamic network structure leads to chirality synchronization if the enantiomerization barrier is sufficiently low, i.e., that racemization drives the development of uniform chirality. Local mirror symmetry breaking leads to conglomerate formation. Total mirror symmetry breaking requires either a proper phase transitions kinetics or minor chiral fields, leading to stochastic and deterministic homochirality, respectively, associated with an extreme chirality amplification power close to the bifurcation point. These mirror symmetry broken liquids are thermodynamically stable states and considered as possible systems in which uniform biochirality could have emerged. A model is hypothesized, which assumes the emergence of uniform chirality by chirality synchronization in dynamic "helical network fluids" followed by polymerization, fixing the chirality and leading to proto-RNA formation in a single process.
\end{abstract}

Keywords: mirror symmetry breaking; biological chirality; liquid crystals; proto-RNA; networks; compartmentalization; chiral liquids; cubic phases; prebiotic chemistry; chirality amplification; helical self-assembly

\section{Introduction-Homochirality and Life}

Ever since Pasteur revealed the molecular asymmetry of organic compounds in 1848 [1], the origin of the homochirality of biologically relevant molecules has attracted considerable attention. The chirality of organic compounds is due to the tetrahedral structure of carbon with a valence of four bondings to adjacent atoms. Only if all four substituents are different, is the compound chiral and existing as two stereoisomers representing mirror images of each other, differing in their configuration, being either $\mathrm{D}$ or $\mathrm{L}$. It is well known that in all existing organisms the carbohydrates exist in the D-form and the amino acids in the L-form (see Figure 1; there are also L-sugars and D-amino acids in biological systems, but if they are involved, they fulfill specific functions, see [2]). This homochirality is considered as a signature of life. In the 4.5 billion years $(\mathrm{Ga})$ of the history of Earth, by 4.2-4.3 Ga Earth has cooled sufficiently to be covered by liquid water. Already by $3.95 \mathrm{Ga}$, the first signatures of life appear as carbon isotope signatures. In this astonishing narrow window of only about 200-300 million years $(0.2-0.3 \mathrm{Ga})$, the first cells came to existence, meaning that mirror symmetry must have been broken and the genetic code developed during this, on a geological time scale, amazingly short period 
of abiogenesis [3]. The origin of the homochirality of the molecules of life and the mechanism of the chirogenesis remain an unsolved problem in the hypotheses of development of life [4-7]. The focus of chirogenesis was mostly on the carbohydrates and amino acids being intrinsically chiral, as described in numerous contributions and reviews [8-23]; amphiphiles were also considered [24]. However, there are also biologically relevant molecules, or at least building blocks of such molecules, which are achiral, because they are built up of carbons with only three substituents, and these compounds with trigonal carbons are flat. Among them, the pyrimidine und purine bases ( $N$-heterocycles) involved in the nucleic acids form the basis of the genetic code of RNA/DNA, which developed during abiogenesis. Helical self-assembly (for example, predominately single helices for RNA and double helices for DNA) is an important consequence of molecular chirality and simultaneously provides a source of homochirality. It does not require molecular chirality, and therefore it can also be formed under achiral conditions with achiral molecules [25-30]. Helical superstructures are not only formed as crystalline assemblies, fibers and gels [31-38], they are also common in soft matter systems and fluids, where they can occur spontaneously $[25,26,39-42]$ or induced by an internal or external source of chirality [43-45]. Soft self-assembly in fluids is of special interest for chirogenesis, as life most likely developed in aqueous fluids.

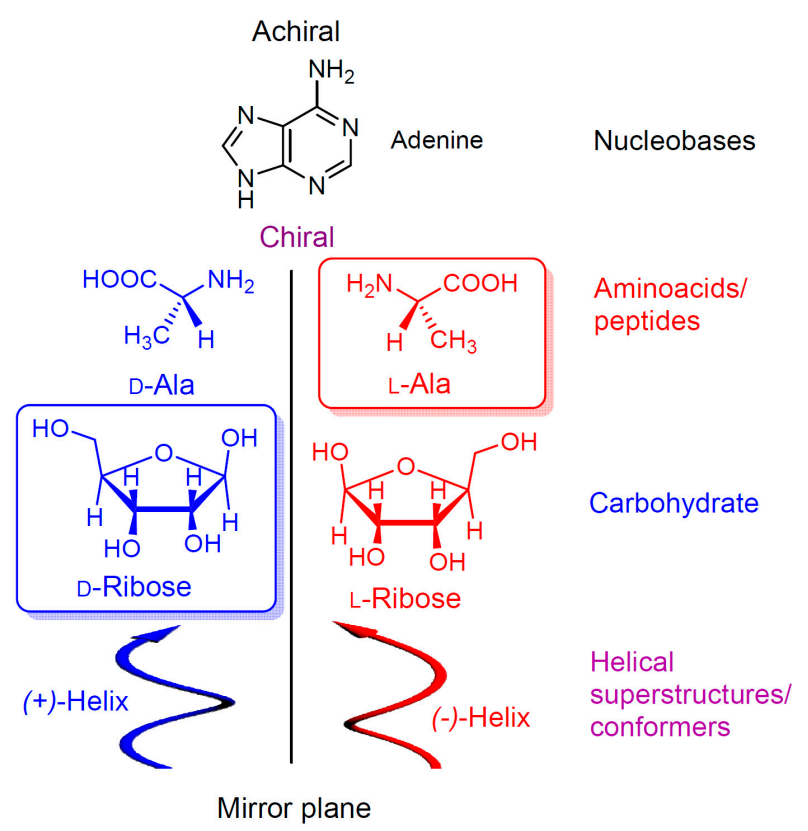

Figure 1. Biologically relevant chiral and achiral molecules and structures.

Herein, the recently discovered spontaneous mirror symmetry breaking in isotropic liquids [25] and in liquid crystalline (LC) cubic phases [26] is discussed under the aspect of their relevance for the emergence of biochirality during abiogenesis. It is postulated that biochirality could have arisen by the spontaneous helical self-assembly of achiral molecules in the liquid state, and that synchronization of the helicity of self-assembled achiral heteroaromatic amphiphiles by the formation of dynamic networks could have been the source of the developing biochirality. It is hypothesized that early forms of RNA could not only have acted as the first information carrier and catalyst in abiogenesis, but could also provided the biochirality.

\section{Emergence of Homochirality in Non-Biological Systems-Artificial Chirogenesis}

\subsection{Racemates vs. Conglomerates}

Based on the fundamentals of stereochemistry, under achiral conditions, chiral molecules are always formed from achiral (prochiral) substrates as racemic mixtures of the two enantiomeric forms in 
1:1 ratio [46]. In these racemic forms, there are intermolecular interactions between the like enantiomers (D/D and L/L) as well as between unlike pairs (D/L) with different energies. Two different situations can be distinguished depending on the strength of the attractive intermolecular interactions between the like (D/D and L/L) and unlike (D/L) pairs.

As shown in Figure 2a,b, the attractive interactions can be either stronger between the opposite enantiomers, leading to a thermodynamically stable racemate (R-type, Figure 2a), or, if the attractive interactions between like enantiomers are stronger, it leads to conglomerates of the two enantiomorphic pairs D/D and L/L as energy minimum states (C-type, Figure 2b). The first case is the predominating in the crystalline state, observed for $90-95 \%$ of the known crystalline compounds [47]. One of the reasons for this is that the entropy gain of mixing contributes to the free energy gain of the racemate, whereas in the case of conglomerate formation, the entropic penalty of demixing must be overcome by the enthalpy gain of the homochiral interactions.

a)

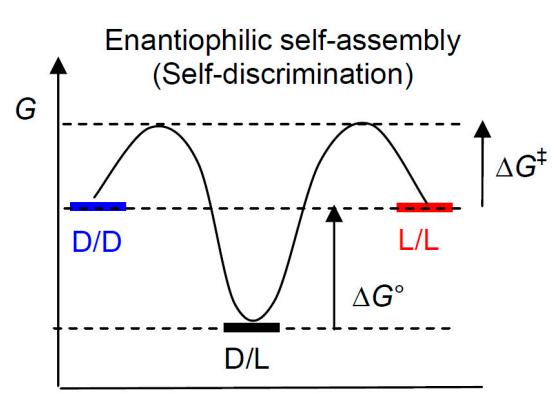

Mirror symmetry breaking:

$\rightarrow$ Requires permanent chirality

$\rightarrow$ Leads to kinetically stabilized homochiral steady states by autocatalysis and cross inhibition b) C-Type Systems

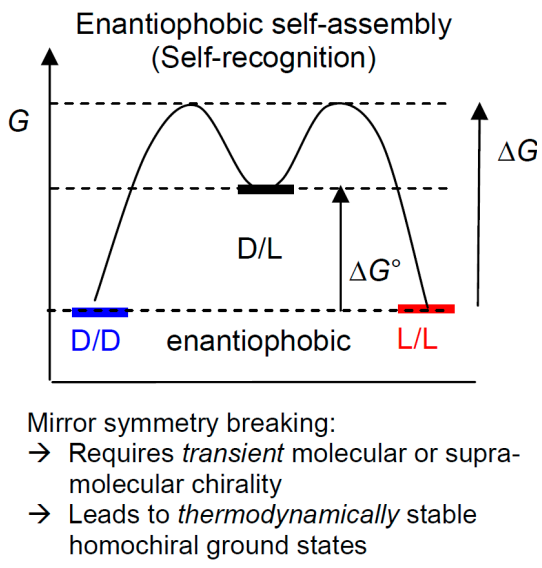

c) Bifurcation and Chirality Amplification

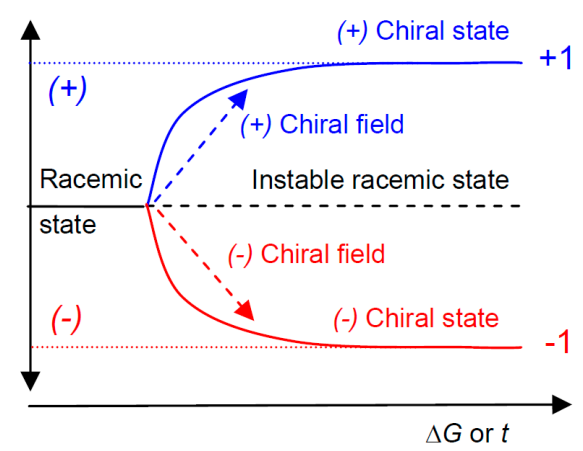

Figure 2. The two systems of relevance for mirror symmetry breaking. (a) R-type systems ( $\mathrm{R}=$ racemate) with stronger attractive forces between the heterochiral enantiomers and low-energy racemic ground state (enantiophilic or social self-assembly), mirror symmetry breaking would require an amplification of the excess enantiomer in scalemic mixture or resulting from statistical fluctuations. (b) C-type systems ( $\mathrm{C}=$ conglomerate) with preferred homochiral interactions (enantiophobic or narcissistic self-assembly), leading to low-energy homochiral states; this allows the formation of thermodynamically stable homochiral ground states, usually representing conglomerates. A third possibility where DD/LL and DL have identical energies is rare and not shown here. A typical feature of both systems is bifurcation into either one of the enantiomeric states, (c) shows the general bifurcation scheme; the achiral (or racemic) state becomes instable and chiral statistical fluctuations drive the system to one of the degenerate enantiomeric states; weak chiral polarization close to the bifurcation point transforms the stochastic bifurcation into a deterministic one. 


\subsection{R-Type Systems: Mirror Symmetry Breaking by Autocatalysis And Enantiomeric Cross-Inhibition in Chemical Reaction Cycles-Soai Reaction}

In the case of stronger attractive interactions between unlike enantiomers, the racemate is thermodynamically more stable than the homodimers D/D or L/L, see Figure 2a. If a scalemic mixture (i.e., a mixture of the enantiomers being different from 50:50\%, the racemate, and from 100:0\%, the pure enantiomer) crystallizes, then the racemate is formed first and the excess enantiomer remains in the melt or solution. In this case, uniform chirality can only arise if the ratio of the enantiomers is not precisely $50: 50 \%$. However, this can even be the case for the racemates, due to the inherent statistical fluctuations. This means that there is always a tiny statistic deviation from the exact 50:50 ratio obtained in chemical reactions under achiral conditions, either with a minor excess of the Dor the L-enantiomer. The enantiomeric excess (ee) is very small and can be calculated according to $\mathrm{ee}=[\mathrm{D}]-[\mathrm{L}] /[\mathrm{D}]+[\mathrm{L}]=0.6743(N)^{-0.5}$, where $N$ is the total number of molecules $[9,48-54]$. This provides the basis of the mechanism of spontaneous emergence of homochirality in chemical systems proposed in 1953 by F. C. Frank [55]. It is based on autocatalysis and inhibition by the formation of an inactive meso-form by $\mathrm{D}+\mathrm{L}$ pairing (enantiomeric cross-inhibition), leaving the pure excess enantiomer acting as the autocatalyst for its own reproduction. The statistical fluctuations lead, in a stochastic way, either to one or the opposite chiral form with equal probability (bifurcation, see Figure 2c). An imbalance arises by chiral dopands or chiral forces (both summarized here as chiral fields) such as circular polarized light and chiral surfaces, which bias one sense of chirality (dotted arrows in Figure 2c) [56]. Soai et al. [57,58] found the first highly efficient asymmetric autocatalysis (non-linear chirality transfer [59]) with a strong positive non-linearity of chirality transfer (amplification of chirality), by using the reaction between pyrimidine-5-carbaldehydes with diisopropyl zinc (Figure 3) [57]. A huge number of weak sources of chirality have been tested, including cryptochiral compounds [60], isotopomers [61] enantiotopic surfaces of crystals [62] and statistical fluctuations [63,64]. An enantiomeric excess (ee) as low as $5 \times 10^{-5} \%$ was found to be sufficient to ensure almost complete enantioselection of $>99.5 \%$ in only three autocatalytic cycles (Figure 3). Though this specific reaction is very unlikely to have played any role in the development of homochirality in nature, it is an important proof of principle. This process can produce chiral molecules in an isotropic solution by chemical reactions under achiral conditions (stochastic) or under the influence of a weak chiral field (deterministic). Usually, in the experiments, the chirality of the products is fixed by crystallization, which makes them long-term stable. However, if kept in solution racemization is likely to occur by the formation of the thermodynamically more stable racemic state and the thus obtained chirality is instable on a geological time-scale [65]. This means that the chiral fluids of R-type systems represent metastable states which must be maintained by continuous autocatalytic cycles and a continuous input of energy, as described in a number of papers $[16,17,55,66,67]$.

\subsection{C-Type Systems: Spontaneous Homochirality}

\subsubsection{Spontaneous Homochirality by Phase Transitions-Viedma Ripening}

Cross-inhibition and autocatalysis are not required for achieving homochirality if the homochiral attractive interactions become preferential over the heterochiral (C-type systems, see Figure 2b) [68-72]. In this case, the homochiral state represents the spontaneously formed energy minimum state and homochirality can emerge spontaneously, leading to conglomerates during crystallization of racemic mixtures, as already shown by Pasteur's famous work [1]. The typical outcome is a conglomerate of both coexisting enantiomeric forms, i.e., only a locally symmetry broken state is formed, but recently methods have been developed to shift this racemic mixture to only one of the enantiomeric states, thus leading to complete mirror symmetry breaking. 


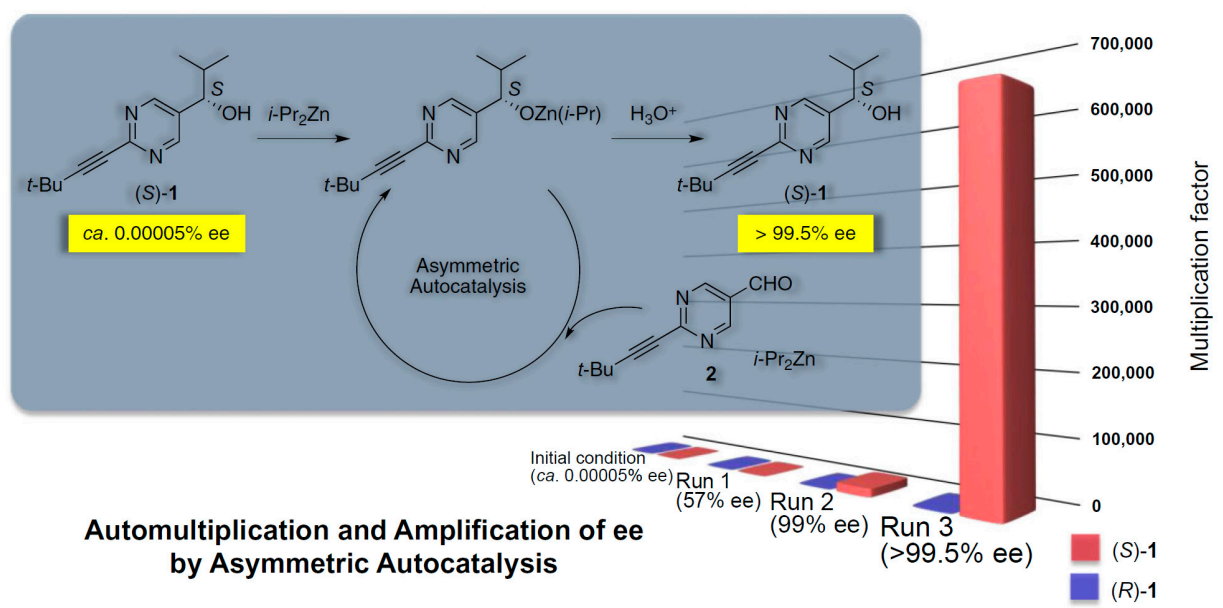

Figure 3. Asymmetric autocatalytic chirality amplification in the Soai reaction leads in only three cycles from (S)-1 with an ee of only $5 \times 10^{-5} \%$ ee to an almost enantiomerically pure compound (S)-1 with $>95 \%$ ee, representing an extreme case of deterministic mirror symmetry breaking in an R-type system [57]. The obtained homochiral enantiomeric product is stabilized and racemization is kinetically inhibited by storage of the obtained compound in the crystalline state. Reprinted from [57], Copyright (2014), with permission from Wiley.

The most prominent example of such a process is the Viedma ripening, which allows the complete deracemization of conglomerates by grinding or thermal cycling with a coexisting solution (Figure 4b) [73-75]. Without going into details, this process is based on the dissolution of smaller crystals and the growth of the lager, combined by their fast racemization in the coexisting solution. In this case, enantiomerization of the minor enantiomer is essential for achieving uniform chirality. This racemization must be sufficiently fast and therefore in most cases requires catalysis for permanently chiral molecules [76]. This can also be used in chemical reactions, where a fast equilibrium between the enantiomeric products and the achiral educts leads to the crystallization of the product in $100 \%$ ee, representing a new method of absolute asymmetric synthesis [77-80]. Likewise, achiral molecules (e.g., $\left.\mathrm{NaClO}_{3}[73,74]\right)$ and transiently chiral molecules with chiral low-energy conformations [42] (e.g., benzil) can crystallize with the formation of only one enantiomeric form of chiral crystals (Figure 4a,c) [81]. A fast racemization kinetics is the basis of the spontaneous mirror symmetry breaking in the case of the C-type systems (Figure 2b), whereas for the R-type systems (Figure 2a) racemization leads to the loss of chirality. Moreover, in all these cases, the mirror symmetry broken state once developed is trapped by crystallization in a 3D lattice which provides a denser packing and freezes the dynamics. This, together with the high degree of cooperativity of the non-covalent interactions between the molecules in the crystalline 3D lattice enhances the enantiomerization energy barrier. Therefore, even for fast racemizing chiral molecular conformers, the chirality sense becomes synchronized and fixed in the crystalline state (Figure 4c). However, in dilute solutions, the interactions with the achiral solvent molecules become the dominant intermolecular interaction (solvatation) and the attractive interactions between like enantiomers cannot stabilize the system. Therefore, in solution, the unfavorable entropy of the homochiral system leads to racemization in timescales depending on the activation energy of racemization. The situation is different for polymers, where the chiral units are covalently fixed to one other and stabilize each other, and therefore the favorable like interactions are also retained in solution, as long as the polymer is not hydrolyzed [82]. 


Chiral crystals of
achiral molecules

Transiently chiral molecules a)

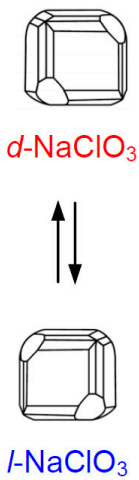

b)
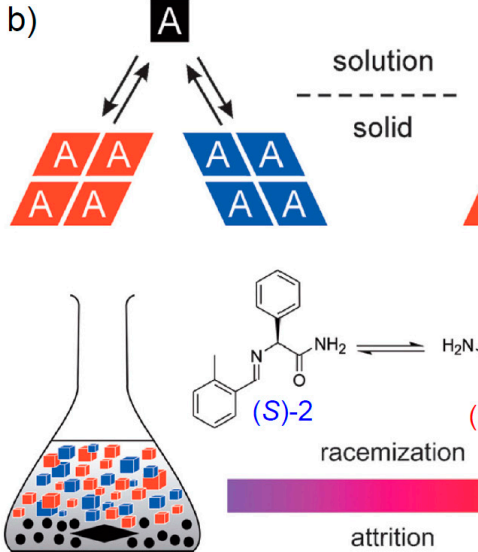

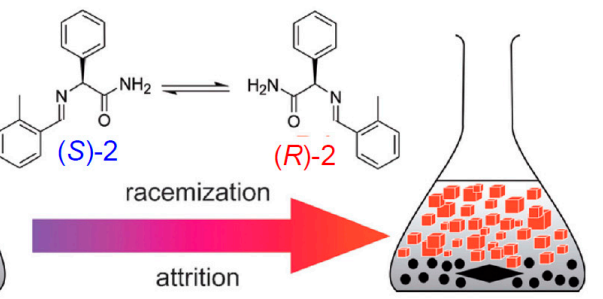

c)

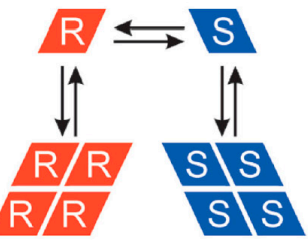
Benzil

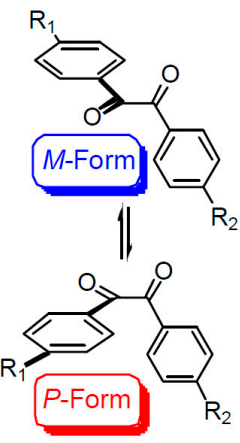

Figure 4. Viedma deracemization. Panel (b) shows the principle scheme for the transformation of a racemic conglomerate of crystals of an achiral (A) or racemic chiral compounds ( $R \leftrightarrow S$ ) in solution by mechanical grinding. [77] (a) shows the example of chiral crystals formed by achiral molecules and (c) an example of a transiently chiral molecule, separated by this process into enantiomorphic crystals; in the crystals, the conformers are chirality synchronized. Note that the color scheme indicating the chirality sense is in this figure opposite to that used in the other figures. (b) is reprinted from [77], Copyright (2009), with permission from Wiley-VCH.

\subsubsection{Spontaneous Mirror Symmetry Breaking in Liquids}

The above-mentioned stabilizing effects of the crystalline state are absent in the melted isotropic liquid state. However, for C-type liquids, the spontaneous bifurcation into two liquids with opposite optical activity was identified by computer simulations $[65,68]$. It was shown that it takes place if (i) the enthalpic gain of deracemization exceeds the entropic penalty of demixing of the enantiomers by $\Delta H=2 k_{\mathrm{B}} T$ (Figure 5), and (ii) if there is a fast enantiomerization kinetics. Both together lead to a synchronization of the chirality sense. The resulting enantiomeric liquids are scalemic and increase in enantiomeric purity with further rising $\Delta H$.

As the stronger attractive interaction between the like enantiomers is likely to lead to a closer packing, the conglomerate formation takes place by a decrease in volume, and therefore it was recently proposed that spontaneous resolution in such liquids could be triggered under sufficiently high pressure $[83,84]$. Nevertheless, attempts to achieve spontaneous separation of enantiomers in the liquid state have failed $[85,86]$ until, in 2014, we discovered the first experimental observation of spontaneous mirror symmetry breaking in the liquid state of transiently chiral molecules (compound 3 in Figure 6), even without any applied pressure [25]. In the meantime, this phenomenon was observed in several other classes of compounds, shown in Figure 6 [40,42,87-90]. In the following sections, the possible reasons for this observation and the potential impact of this finding for the emergence of uniform biochirality will be discussed. 


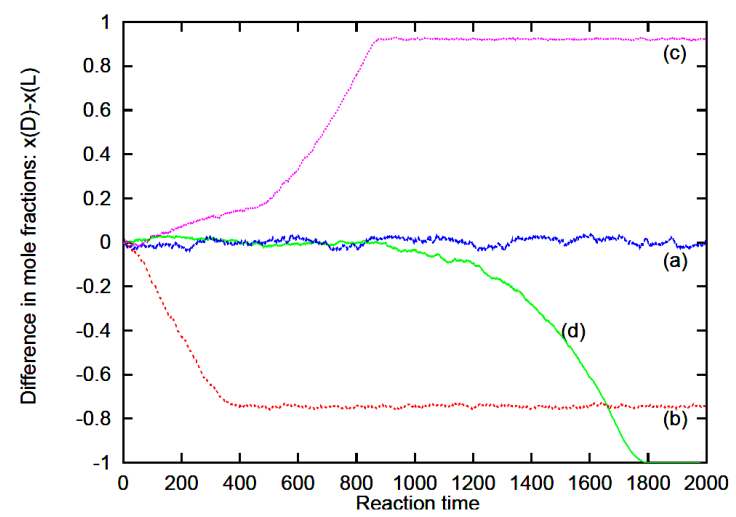

Figure 5. Enantiomeric excess as a function of time in a molecular dynamic system with isomerisation kinetics and for different enthalpy gains for the chirality synchronization process with (a) $|\Delta H|=R T$, (b) $2 R T$, (c) $3 R T$ and (d) $\infty$; reprinted from [65].
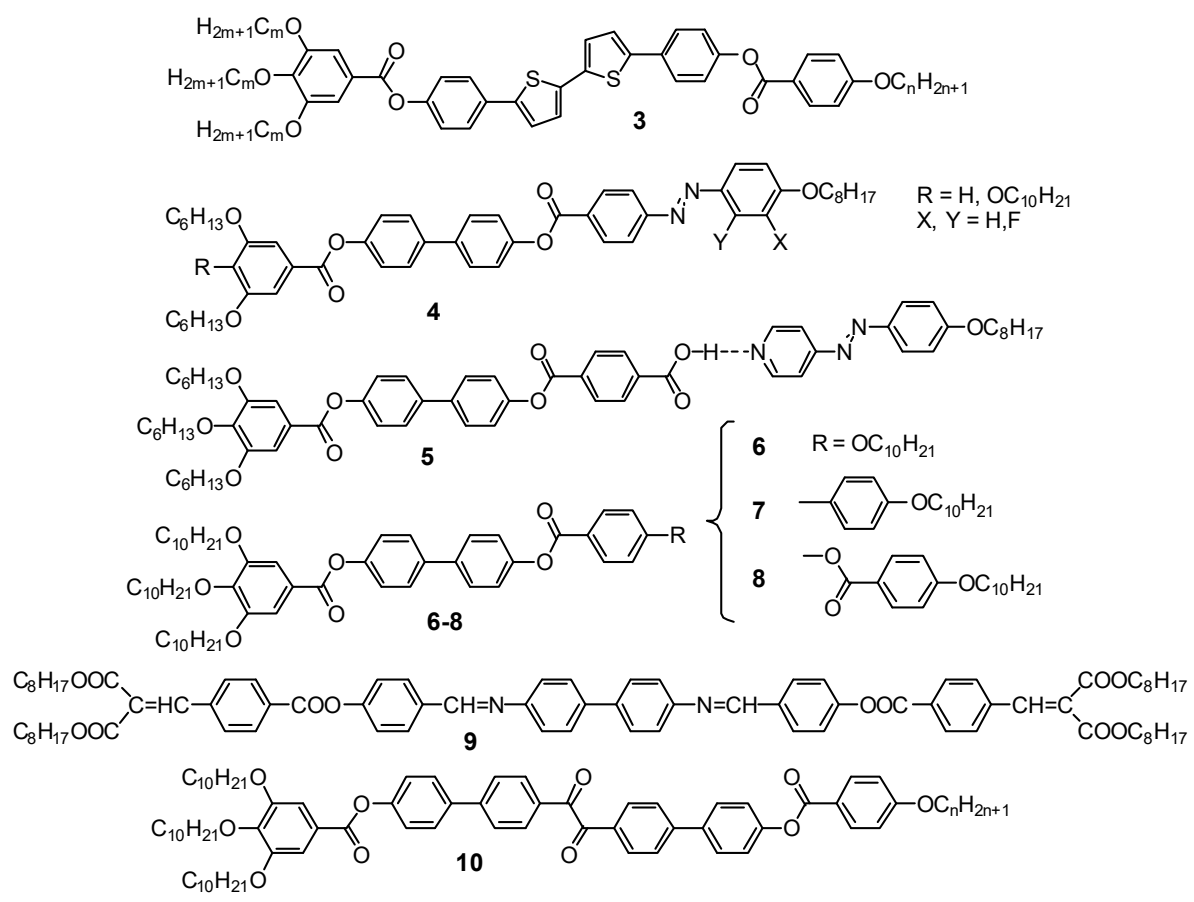

Figure 6. Molecular structures of compounds capable of mirror symmetry breaking in the isotropic liquid state (Iso ${ }^{[*]}$ phases) $[25,26,87-90]$.

\section{From Crystals via Liquid Crystals to Liquids}

Liquid crystals (LCs) represent intermediate states between ordinary liquids and the crystalline state combining order and mobility; the order can be either orientational or positional or a combination of both [91-93]. This leads to a huge variety of LC states, a small selection of the most important phase structures, those of relevance for the discussion herein, are collated in Figure 7a-f. The simplest LC phase is the nematic phase (Figure 7a), which has only orientational order and makes the physical properties of the liquid direction-dependent [94]. Emerging positional order can occur in one, two or all three spatial dimensions, leading to lamellar (smectic), columnar and bicontinuous cubic ( $\left.\mathrm{Cub}_{\mathrm{bi}}\right)$ phases, respectively (Figure 7b-f). The most complex LC phases are the Cub bi phases, which develop at the transition between lamellar (1D) and columnar (2D) self-assembly [95-102]. These Cub bi phases with a 3D lattice represent networks of branched columns. Due to the intrinsic combination of mobility and order, all three modes of LC self-assembly are of relevance for biosystems [103-109]. The lamellar structures are the basis of all cell membranes [110,111]: columnar phases allow the dense 
packing of DNA in the nucleus [112-115] and cubic phases are involved in cell fusion and cell fission processes $[95,102]$. The positional order is mainly a consequence of the segregation of incompatible molecular building blocks into separate nano-spaces (microsegregation or nanosegregation $[93,97,116]$ ), i.e., these compounds represent amphiphiles, which are composed of two chemically connected incompatible parts (Figure 7g) [97]. However, the amphiphilicity is not restricted to the well-known polar/lipophilic amphiphilicity, as commonly known for lipids and their aqueous systems (Figure 7h); it can arise from any incompatibility of intermolecular interactions, and the second most common is the incompatibility between rigid polyaromatic and flexible aliphatic building blocks $[93,97,117]$. In all cases, this segregation creates interfaces which determine the morphology of the aggregates and the dimensionality of long-range positional order on an $\mathrm{nm}$-scale (Figure $7 \mathrm{~b}-\mathrm{f}$ ). The remarkable feature of all LCs, which distinguishes them from the solid-state crystals, is the absence of any fixed position of the individual molecules, which is identified by the typical diffuse scattering around $4.5 \mathrm{~nm}$ observed in their X-ray diffraction patterns. This means that despite the presence of long-range order, the individual molecules are still mobile and thus can be considered as ordered fluids. However, due to the order, the molecules are not completely independent, but more or less fixed in lamellar or columnar aggregates or even in networks (Cub bi phases), and this provides a confinement for the molecules and cooperativity of the intermolecular interactions in one, two or even three directions $[42,117,118]$. Consequently, mirror symmetry breaking is supported and stabilized in the LC state compared to the isotropic liquid state, and there are numerous recent reports of spontaneous mirror symmetry breaking in LCs. These have been summarized and discussed in previous reviews [40-42,119].

We focus here only on those observed in the $\mathrm{Cub}_{\mathrm{bi}}$ phases, which are of relevance for the following discussions $[95,96]$. Bicontinuous means that there is a continuum and additional continuous networks, independent of the actual number of these networks. The networks are distinct by the valence of their junctions (mostly three, but also four and six [96]) and the number of networks per unit cell (in most cases two [96,120], but in some cases also one [121,122] or three [123]). Figure $7 \mathrm{~d}-\mathrm{f}$ shows the case of networks with three-way junctions which are the most common, namely the single gyroid, the double gyroid and the more complex I23 phase. To date, only the double network (the gyroid, Ia3d) and the triple network (I23) [123] are known for liquid crystalline $\mathrm{Cub}_{\mathrm{bi}}$ phases with three way junctions (Figure $7 \mathrm{~d}, \mathrm{f}$ ). The continuum is, in most cases, either formed by a solvent (in most cases water) in the so-called lyotropic systems, or by flexible chains, in most cases alkyl chains, in the solvent-free thermotropic systems. The fluidity of solvents or chains contributes significantly to the mobility and to the segregation of networks and continuum. However, in the networks the organization is liquid-like, not crystal-like, i.e., liquid crystalline $\mathrm{Cub}_{\mathrm{bi}}$ phases are dynamic and therefore very different from the networks in gels which are crystallized $[29,31,32]$. 

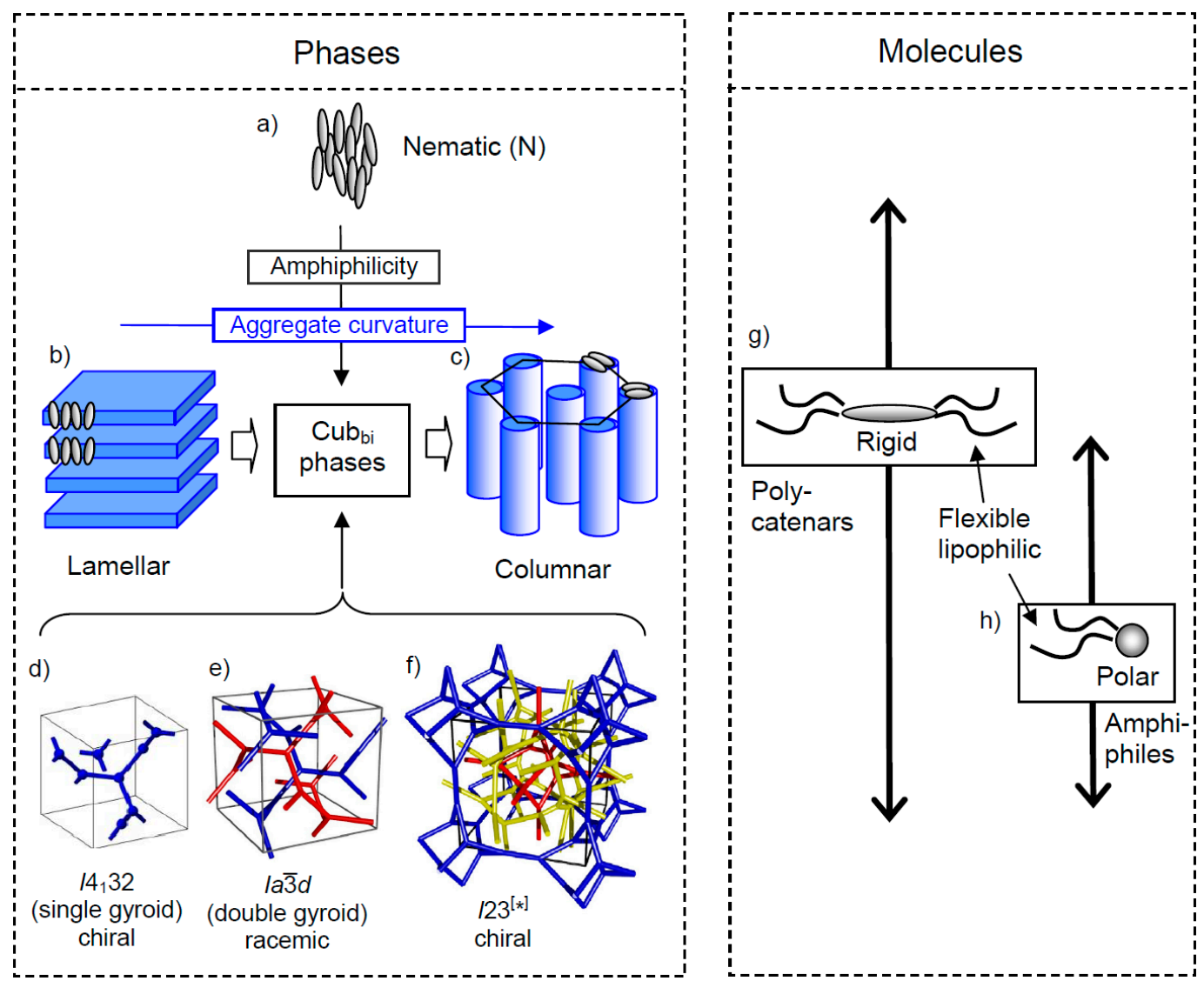

Figure 7. Development of liquid crystalline (LC) phases depending on molecular amphilicity and supramolecular aggregate curvature. (a) Nematic phase formed by non-amphiphilic rod-like molecules showing exclusively orientational order while retaining liquid-like fluidity. $(\mathbf{b}-\mathbf{c})$ Transition from lamellar via bicontinuous cubic $\left(\mathrm{Cub}_{\mathrm{bi}}\right)$ phases to columnar phases by increasing interface curvature between the nano-segregated compartments, as observed for polycatenars compounds. The Cub $\mathrm{bi}_{\mathrm{b}}$ phases are specified in $d-f$ showing cubic phases with three-way junction networks. (d) The single gyroid is yet unknown for LC systems; (e) the double gyroid is the commonly observed Cub bi phase for a wide range of self-assembled systems, ranging from lyotropic systems to bulk self-assembly of low molecular weight and polymeric amphiphiles; (f) the complex triple network structure with I23 lattice is exclusively formed by rigid $\pi$-conjugated molecules crystals, replacing the Ia3d phase for a distinct range of chain volume. For the single- and double-network structures, four- and six-way junctions are also possible, which are not shown. Panels (g,h) show two typical molecular structures forming $\mathrm{Cub}_{\mathrm{bi}}$ phases, the arrows indicate the LC phase types covered by these compounds. (f) is reprinted from [123], Copyright (2020), with permission from RSC.

These $\mathrm{Cub}_{\mathrm{bi}}$ phases are special among the LC phases for several reasons. Firstly, due to the cubic symmetry, they are isotropic like ordinary liquids. Due the optical isotropy, they do not show any linear birefringence, and hence, optical activity and mirror symmetry breaking can be easily be detected by the rotation of the plane of linear polarized light. Under a polarizing microscope, which can be considered as a polarimeter with spatial resolution, a chiral conglomerate appears as a pattern of dark and bright domains for the areas with opposite chirality after a slight rotation of one polarizer out of the $90^{\circ}$ crossed orientation by $1^{\circ}-10^{\circ}$ in a clockwise or anticlockwise direction. The brightness is inverted by inverting the twist direction of the polarizers (see Figure 8e,f) [26]. Secondly, Cub bi phases represent supramolecular network structures in a continuum, and networks are responsible for the development of complexity and emergence of new properties [124]. In the case discussed here, the self-assembled molecular 3D network structure leads to the emergence of mirror symmetry breaking due to the improved pre-organization of the involved molecules and the thus increasing intermolecular 
interactions and arising cooperativity [116,118]. The network structure leads to a transmission of chirality in all three spatial directions. Moreover, the inherent mobility allows a fast enantiomerization kinetics, which is required for mirror symmetry breaking in fluids.
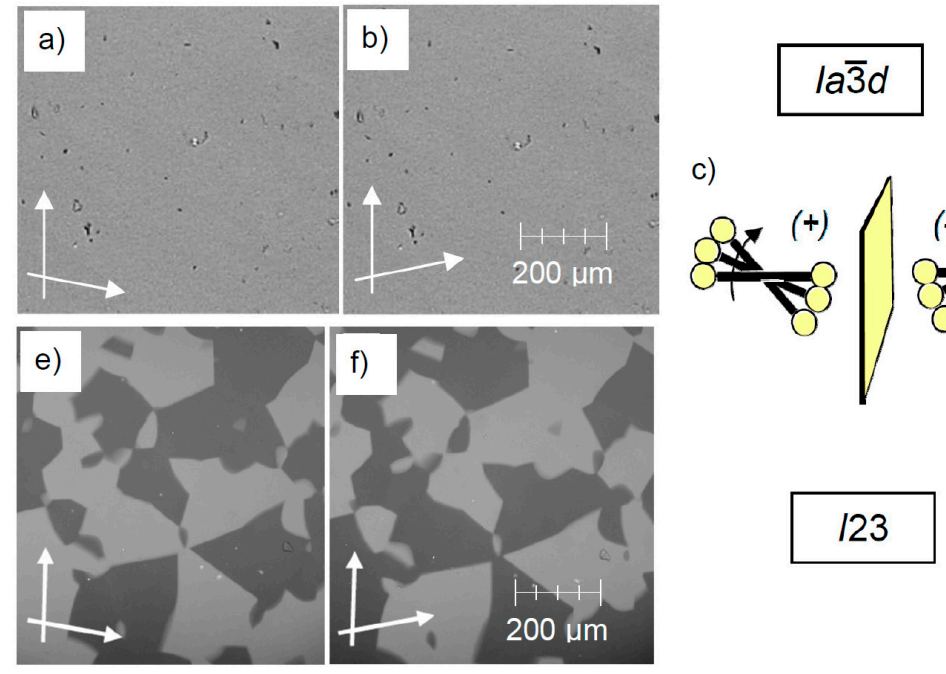

d)
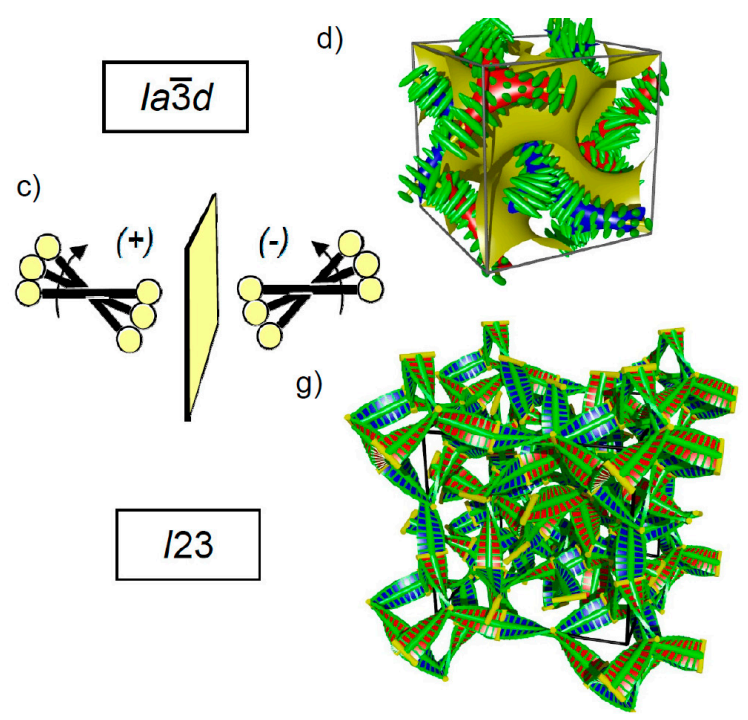

Figure 8. Mirror symmetry breaking in the Cub bi phases. In $(\mathbf{a}, \mathbf{b})$ and $(\mathbf{e}, \mathbf{f})$ the textures as observed under a polarizing microscope with the indicated orientation of the polarizers (white arrows) are shown [26], and (c,d,g) show the models of molecular organization. (c) shows the helical twist of the molecules along the networks, which can be right- or left-handed. $(\mathbf{d}, \mathbf{g})$ show one unit cell of the cubic phases; the yellow interfaces in (d) represent the minimal surfaces separating the two networks; the green rods in (d) and in ( $\mathbf{g}$ ) the yellow rods and the thin green lines parallel to these rods indicate the rod-like units organized in a helical manner [123]. Panels $(\mathbf{a}, \mathbf{b}, \mathbf{d})$ show the achiral double network $\mathrm{Cub}_{\mathrm{bi}}$ phase with Ia3d space group. Panels $(\mathbf{e}-\mathbf{g})$ show the chiral triple network Cub $\mathrm{b}_{\mathrm{bi}}$ phase with I23 space group; adapted from [26], (g) is reprinted from [123], Copyright (2020), with permission from RSC.

\section{Mirror Symmetry Breaking in Cubic Network Phases}

\subsection{Racemic Ia3d Phases and Chiral Conglomerate Type I23 Phases}

Though there are numerous different materials capable of forming thermotropic or lyotropic $\mathrm{Cub}_{\mathrm{bi}}$ phases $[92,93,99,100]$, the focus is here on the thermotropic Cub bi phases formed by compounds having flexible chains at one or both ends of a rod-like polyaromatic core (see Figure 6). In the Cub bi phases of these so-called polycatenar molecules [125-127], the rods are organized in networks and the terminal chains form the continuum between them [26,42]. Within the networks, the rods tend to be organized, on average, parallel to each other and perpendicular to the networks (Figure $8 \mathrm{~d}, \mathrm{~g}$ ). However, due to the larger space required by the end-chains compared to the rods, they cannot align perfectly parallel, but assume a helical twist (Figure 8c), which is transmitted by the junctions throughout the networks. In this way, dynamic supramolecular helix networks develop, with the helix sense being synchronized along the networks (Figure 8d,g) [26,42].

Depending on the number of networks, the symmetry of the cubic lattice is different. The Ia3d lattice is formed by two enantiomorphic helical networks with three-way junctions being twisted to each other by $70.5^{\circ}$ (Figures 7e and 8d) [26]. This means that the networks themselves are homochiral and two networks with opposite handedness are combined in the Ia3d lattice, thus becoming overall achiral, despite the presence of a helical superstructure in the networks. The second type of cubic phases observed for this kind of compounds has the space group $\operatorname{Im} 3 m$, which is achiral and formed by three networks (Figure 8g) [26,123]. In this case, the network chirality cannot compensate and there is a synchronization of the helicity in all three network, leading to the chiral space group I23. 
$\mathrm{All} \mathrm{Cub}_{\mathrm{bi}} / \mathrm{I} 23$ type phases investigated to date show spontaneous mirror symmetry breaking under all conditions, though they are formed by achiral molecules $[26,40,42,87-90,128-133]$. The chirality is detected as described above by investigation under the polarizing microscope by the formation of a conglomerate composed of dark and bright domains due to the rotation of the polarization plane of the light into opposite directions (Figure $8 \mathrm{e}, \mathrm{f}$ ) $[26,40,42]$. The high optical rotation is about $1-2^{\circ} / 10 \mu \mathrm{m}$ (corresponding to about $10,000-20,000^{\circ} / \mathrm{dm}$ ), mainly due to the exciton coupling between the twisted $\pi$-conjugated rods $[134,135]$. In contrast, the achiral Ia3d phase remains uniformly dark after rotating one of the polarizers in either direction, confirming that it is optically inactive (Figure 8a,b). This shows that the network formation in the LC Cub bi phases, transmitting chirality and disfavouring helix reversals [136], is a powerful tool for achieving mirror symmetry breaking under thermodynamic equilibrium conditions and for the long-term stabilization of the chirality synchronized helices in the LC network phases with cubic $[26,88,89,128-133]$ or non-cubic symmetry $[137,138]$. It is noted that the first report on mirror symmetry breaking in cubic phases came from Kishikawa et al. though the structure of the cubic phase and the origin of chirality remained unclear at that time [139]. Overall, the Ia3d phase can be considered as an R-type and the I23 phase as a C-type Cub $\mathrm{b}_{\mathrm{bi}}$ system. Only in C-type systems can mirror symmetry breaking be expected to be achieved by transiently chiral molecules or aggregates in fluid systems under thermodynamic control (Figure 2a,b). Such C-type I23 triple network structures have, to date, only been observed for systems involving sufficiently long rigid polyaromatic units [26], whereas flexible amphiphiles of any kind prefer the organization in the R-type double gyroid (Ia3d) cubic phases [93,96,99-101].

\subsection{Conglomerate Formation vs. Complete Mirror Symmetry Breaking in Cubic Pases}

As shown in Figure 2c mirror symmetry breaking leads to a bifurcation with stochastic outcome, i.e., either one or the other enantiomer becomes dominating, depending on the statistical fluctuations in the considered system. For fast isomerizing systems, these fluctuations modulate locally in space and with time $[48,52,56]$. Therefore, as shown in Figure 8e,f, conglomerates of chiral domains with opposite handedness are usually observed, not a uniform chirality of the complete sample. Thus, mirror symmetry breaking is usually only local and takes place under compartmentalization of the sample, where the size of the chiral domains depends on many parameters. Strictly speaking, this is only a local mirror symmetry breaking which, on a larger macroscopic scale, still retains a non-symmetry broken overall racemic state.

Symmetry breaking becomes complete, i.e., only one sense of chirality can be observed in the considered system, if the seed formation at the Iso-I23 transition is slow and the following growth of the uniform domains is sufficiently fast that only one seed determines the chirality sense of the complete sample. However, whether mirror symmetry breaking is considered as complete or only local depends on the size of the actually investigated system. In the case of the Cub $b_{b i}$ phases, the investigations are usually carried out with $10-50-\mu \mathrm{m}$-thick films between two glass substrates and, in this case, the size of the uniformly chiral areas can easily become as large as one to few square millimeters. However, on a larger length scale, conglomerate formation is still observed as soon as more than only one initial seed is formed, and its chirality sense is determined by the local fluctuations (stochastic symmetry breaking). However, the development of uniform chirality is easily triggered by tiny internal or external chiral fields (Figure 2c) [25]. Tiny sources of chirality by (often not detectable) traces of chiral impurities or chiral physical forces can thus lead to only one or the other enantiomer in the whole investigated system, leading to complete deterministic mirror symmetry breaking.

The parity violation is a potential universally acting chiral field, but its effect on mirror symmetry breaking has not yet been unambiguously confirmed experimentally [140] and is considered as unlikely [141]. This effect is much smaller than $k_{\mathrm{B}} T$ and therefore has no measurable influence, at least in non-polymeric systems. Overall, chiral conglomerate formation is considered as an indication of the capability of the considered system of spontaneous mirror symmetry breaking in a finite system. 


\section{Experimental Demonstration of Mirror Symmetry Breaking in Isotropic Liquids}

\subsection{Local Mirror Symmetry Breaking by Conglomerate Formation}

The first experimental proof of a spontaneous mirror symmetry breaking in the liquid state, occurring even in the absence of any applied pressure and at temperatures compatible with the conditions of abiogenesis, was observed for liquid phases occurring in the vicinity of the $\mathrm{Cub}_{\mathrm{bi}}$ phases of polycatenar molecules, like compounds 3 [25]. The molecules forming these mirror symmetry broken liquids are achiral (Figure 6), but can assume energy minimum chiral conformations which are in a rapid equilibrium (transiently chiral molecules, Figure 9a,b) [42].
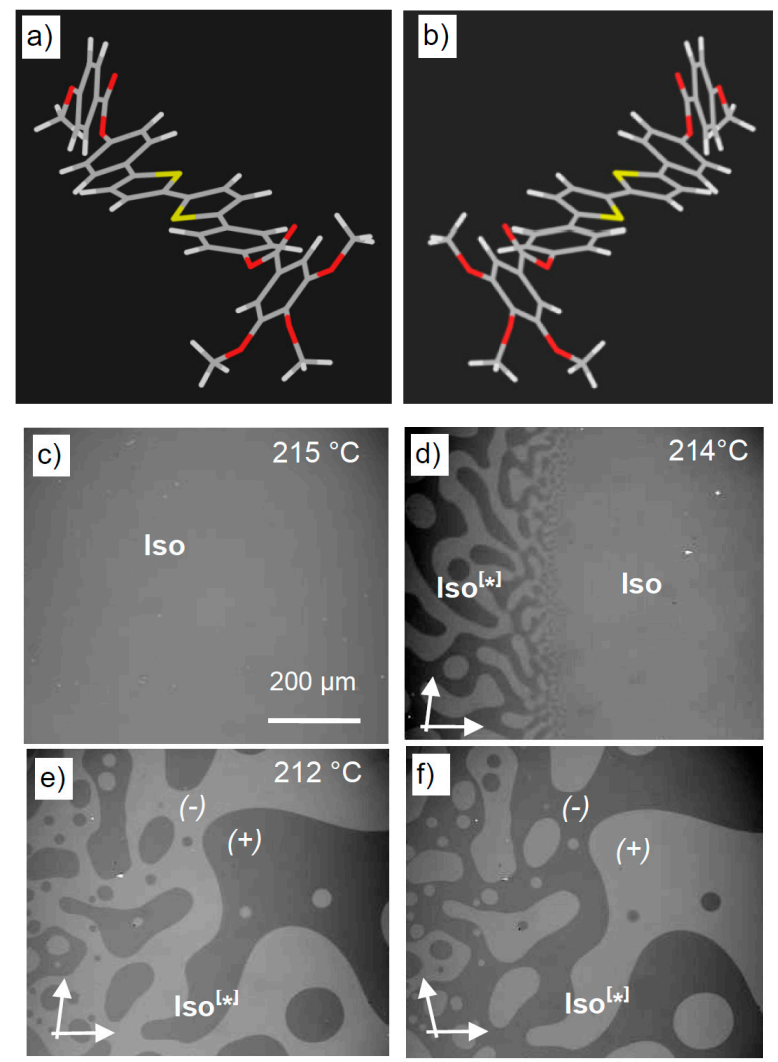

Figure 9. The liquid phases of the polycatenar compounds 3. (a,b) Molecular models showing the helical conformers of a model compound 3 with $m, n=1$; (c-f) Transition from the achiral isotropic liquid to the mirror symmetry broken Iso ${ }^{[*]}$ phase as observed for compound 3 with $m, n=6$ on cooling between slightly uncrossed polarizers; (c) achiral Iso phase, (d) transition Iso-Iso ${ }^{[*]}$ at $214^{\circ} \mathrm{C}$ showing spinodal decomposition at the phase boundary (there is a temperature gradient in the sample with slightly higher temperature at the right), and $(\mathbf{e}, \mathbf{f})$ fully segregated chiral domains in the Iso ${ }^{[*]}$ phase at $212{ }^{\circ} \mathrm{C}$, inverting the brightness by uncrossing the polarizers either by clockwise or anticlockwise rotation; adapted from [25].

As shown in Figure 9c-f, the optically isotropic liquid phase (Iso) spontaneously becomes mirror symmetry broken at a phase transition by the formation of a conglomerate of liquid domains with opposite signs of optical rotation (Iso ${ }^{[*]}$ phase). This process is completely reversible without any visible supercooling effect, even at high heating/cooling rates. The spinodal decomposition confirms the first-order nature of the phase transition. At this phase transition, there is no visible change in the viscosity, i.e., the Iso ${ }^{[*]}$ phase is also a true liquid which flows under gravity, as shown in a video attached as supporting information to [25].

The liquid state is additionally confirmed by X-ray scattering (XRD). The XRD patterns show only a diffuse scattering in the small- as well as in the wide-angle range, excluding the formation of a 
cubic phase [25]. The shape of the diffuse small-angle scattering changes continuously and becomes continuously narrower across the Iso-Iso ${ }^{[*]}$ transitions, but without any visible discontinuity [25]. This supports the liquid state of the material and indicates a spontaneous separation process, leading to a macroscopic conglomerate of two chemical identical, but immiscible liquids differing only in the direction of the rotation of the plane of polarized light [25]. In this case, spontaneous mirror symmetry breaking takes place under thermodynamic equilibrium conditions, leading to a conglomerate of two chiral liquids which is stable, even at temperatures as high as $>200{ }^{\circ} \mathrm{C}$. This demonstrates for the first time that in dynamic systems chirality can develop spontaneously from achiral molecules under thermodynamic control [25]. In the meantime, this was found for a number of different polycatenars molecules (Figure 6) [25,88,89,130], hydrogen-bonded aggregates 5 and even for simple heterocyclic compounds with relationships with nucleobases (see Section 6 below). Even photoisomerizable compounds were found, for which the chirality can be switched on and off by non-polarized visible light (compounds 4, 5 in Figure 6) [88-90].

\subsection{Total Mirror Symmetry Breaking in Isotropic Liquids}

Typically, the formation of the chiral Iso ${ }^{[*]}$ phase takes place by a spinodal demixing at the Iso-Iso ${ }^{[*]}$ transition where, due to local fluctuations, small left- and right-handed domains spontaneously emerge in 1:1 ratio (Figure 10a). The domains rapidly grow and fuse with the formation of larger domains with uniform chirality as a result of the reduction in the interfacial areas between the oppositely chiral domains and the minimization of the curvature of these interfaces (see Figure 10b).
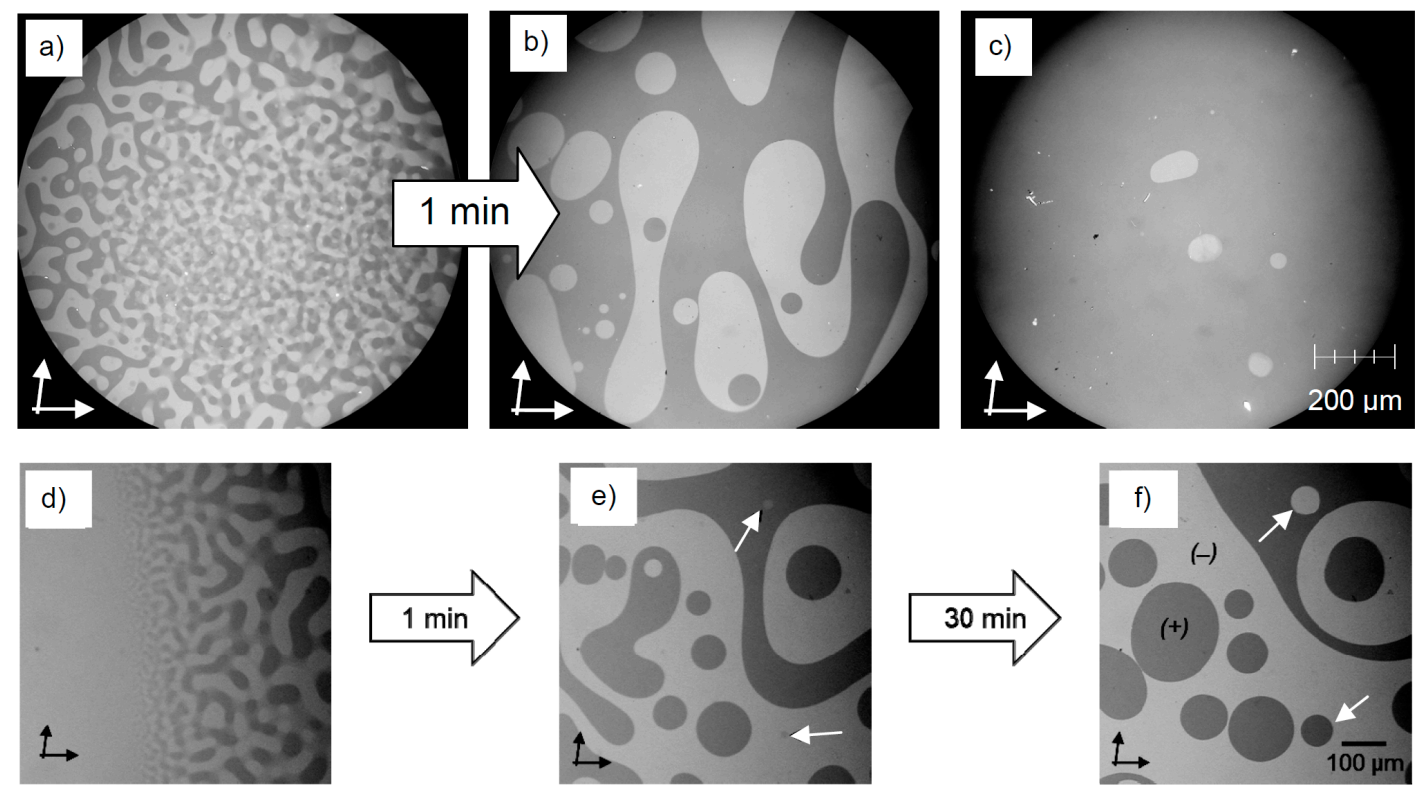

Figure 10. Growth of the size of the chiral domains in the Iso ${ }^{[*]}$ phases of compounds 3 with time. $(\mathbf{a}, \mathbf{b})$ After the transition from the achiral Ia3d phase to the mirror symmetry broken Iso ${ }^{[*]}$ phase of compound 3 with $m, n=6$ on heating; (a) developing chiral domains immediately after the phase transition Ia $3 d-$ Iso $^{[*]}$ at $T=205^{\circ} \mathrm{C}$ and (b) after one min at $T=210{ }^{\circ} \mathrm{C}$; (c) shows an example for the spontaneous imbalance of left- and right-handed domains associated with Iso ${ }^{[*]}$ phases occurring besides a chiral $I 23$ phase (compound 3 with $m=10$ and $n=8) ;(\mathbf{d}-\mathbf{f})$ show the Iso-Iso ${ }^{[*]}$ transition on cooling of compound 3 with $m=n=6$, (d) at the phase transition at $T=212{ }^{\circ} \mathrm{C}$ and $(\mathbf{e}, \mathbf{f})$ after growth for one and $30 \mathrm{~min}$ at $\mathrm{T}=190{ }^{\circ} \mathrm{C}$, respectively; note that the growth of the small circular domains which is indicated with arrows (previously unpublished results).

Toxvaerd proposed that these chiral liquids show an intrinsic tendency to destabilize the racemic state and only one homochiral state will appear when one of the chiral domains encapsulates the other $[19,68]$. The argument is that the enantiomerization takes place at the interface, whereas the 
chirality synchronization inside the chiral domains slows down the kinetics, which enhances the segregation of the enantiomers, i.e., the molecules at the surface are activated. In a droplet of an L-rich domain in the D-rich continuum, the activated molecules at the interfaces have a larger probability to assume the chirality sense of the molecules on the convex side of the droplet (outer side towards the continuum), which experience an excess of D-enantiomer and the droplet will shrink and finally disappear [19]. However, this could not be confirmed experimentally. In our case, the opposite was found: the droplets grow with time (Figure $10 \mathrm{a}, \mathrm{b}, \mathrm{d}-\mathrm{f}$ ) and then fuse to larger domains. This takes place in the D-rich and L-rich regions, and the growth process slows down with growing domain size and decreasing curvature of the inter-domain interfaces (Figure 10e,f). After a certain domain size is reached, no further changes can be observed. This means that the system apparently tends to retain the overall racemic conglomerate state (at least in laboratory timescales) as long as there is no imbalance right from the beginning due to any kind of a biasing chiral field. However, this cannot be stated with certainty, due to the dramatic slowdown of the agglomeration process as the interfacial curvature between the domains decreases. Hochberg and Zorzano have simulated the effect of spatio-temporal fluctuations on the Frank chiral amplification model and obtained two solutions, one leading to uniform chirality and absolute symmetry breaking (Figure 11a) and a second one leading to a racemic state with a linear phase boundary (Figure 11b) [52]. The latter was found to occur in two dimensional systems. Therefore, it must be considered that the experimentally investigated system is a relatively thin film $(10-50 \mu \mathrm{m})$ between two substrates and, in this case, it could behave like a two dimensional system which stacks in the racemic case, whereas in true 3D systems, homochirality might be the final outcome. It is noted here that, once a homochiral liquid has been formed (either under a chiral field or spontaneously after transition from a homochiral $\mathrm{Cub}_{\text {bi }}$ phase, see below), this liquid is stable and no racemization could be observed.
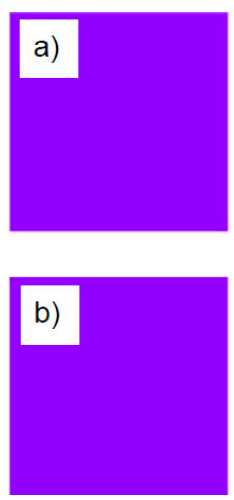
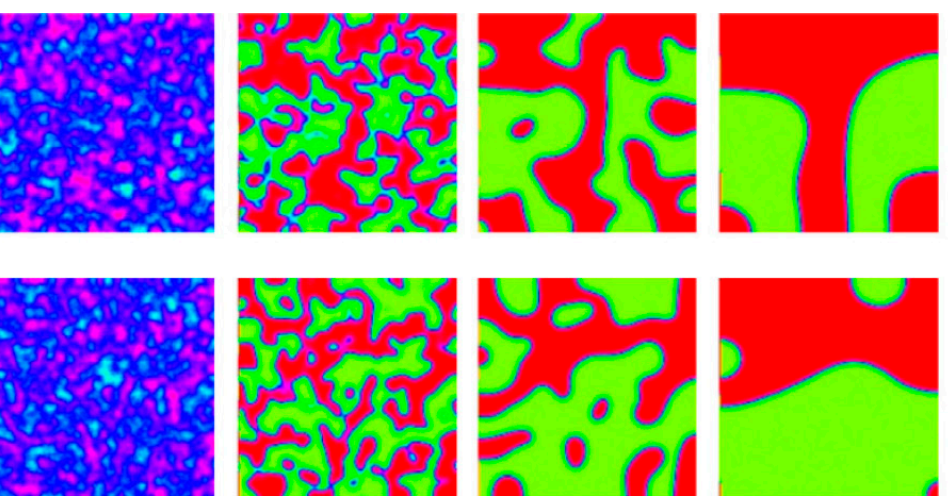

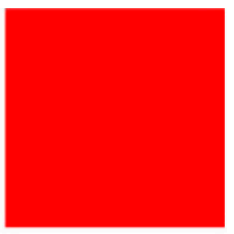

Figure 11. Results of simulations using the exact Langevin equations. Starting from a homogeneous racemic condition (left) the local fluctuations drive the system (a) to a homochiral state (right) or (b) to a state with spatial segregation (right); time runs from left to right. Reprinted from [52], Copyright (2006), with permission from Elsevier.

\subsection{Effects of Dilution on Mirror Symmetry Breaking in Isotropic Liquids}

It is also worth noting that these liquid conglomerates tolerate the addition of achiral molecules, such as, for example, $n$-alkanes, which can even expand the Iso ${ }^{[*]}$ phase temperature range [25]. As shown in Figure 12, up to $50 \mathrm{~mol} \%$ of a long-chain $n$-alkane $\left(\mathrm{C}_{32} \mathrm{H}_{66}\right)$ is tolerated. This is important with respect to the discussion of the possible impact of chirality synchronization in the isotropic liquid state on the emergence of homogeneous chirality in aqueous prebiotic fluids. 
a)

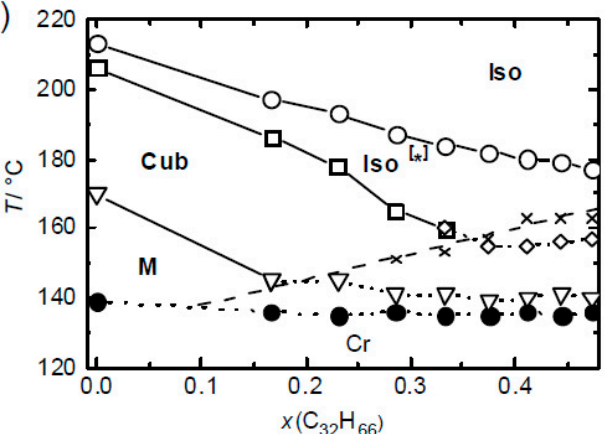

b)

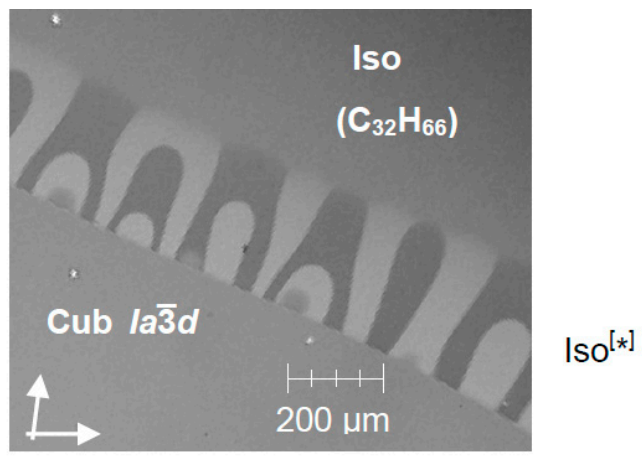

Figure 12. Effect of an achiral hydrocarbon solvent on the Iso ${ }^{[*]}$ phase range of compound 3 ( $m=n=6$, see Figure 6); (a) shows the development of the phase ranges depending on concentration of the hydrocarbon $\mathrm{C}_{32} \mathrm{H}_{66}$ and temperature and (b) shows the contact region as observed under a polarizing microscope at $T=200{ }^{\circ} \mathrm{C}$ (orientation of polarizer and analyzer indicated by arrows), showing the development of the mirror symmetry broken Iso ${ }^{[*]}$ phase between the achiral Ia3d phase (bottom) and the achiral hydrocarbon solvent (top); reprinted from [25].

\subsection{Chirality Amplification in Isotropic Liquids}

Under strictly achiral conditions, the area ratio of the domains is 1:1 in the liquid conglomerates, but chiral dopands with a concentration as low as only $10^{-8} \mathrm{~mol} \%$ can shift the ratio of the domains to a clearly visible imbalance, whereas $10^{-3} \mathrm{~mol} \%$ is sufficient to produce homochirality [25]. Thus, these conglomerates have a huge chirality amplification power, comparable with those observed for the Soai reaction, and weak chiral influences can easily lead to homochirality. The effect of chiral dopands is the most efficient if it is present at the phase transition temperature (Iso-Iso ${ }^{[*]}$ or Iso-I23), i.e., close to the bifurcation point (Figure 2c); below this transition, the effects become much smaller.

\subsection{Total Mirror Symmetry Breaking in the $\mathrm{Cu} b_{b i} / 23$ Phase}

Complete mirror symmetry breaking (homochirality) in the absence of any chiral field can be achieved by a phase transition from the chiral Iso ${ }^{[*]}$ phase to a chiral cubic $I 23$ phase if the formation of the seeds of this cubic phase is a slow process and the transition Iso ${ }^{[*]}-\mathrm{Cub}_{\mathrm{bi}} / 223$ is significantly faster, as shown in Figure 13a-d. In the ideal case, a single seed, which develops either in a (+)- or (-)-liquid domain, leads to uniform chirality in the whole sample, thus leading to complete mirror symmetry breaking. Although the growth of the $I 23$ phase is faster in the regions with the same chirality, it moves the domain boundaries into the areas with opposite chirality and thus leads to an inversion of the chirality in these regions (see Figure $13 a \rightarrow b \rightarrow c$ ), finally providing uniform chirality (Figure 13d). Although this growth is slower, because it requires helix inversion at the moving interfaces, the whole process shown in Figure 13a-d takes place within less than 10 s. Occasionally homochirality can also be found at the transition from the achiral isotropic liquid to the I23 phase on cooling, which is, however, difficult to detect, because in the absence of the conglomerate texture, no significant optical change is visible at the phase transition. 

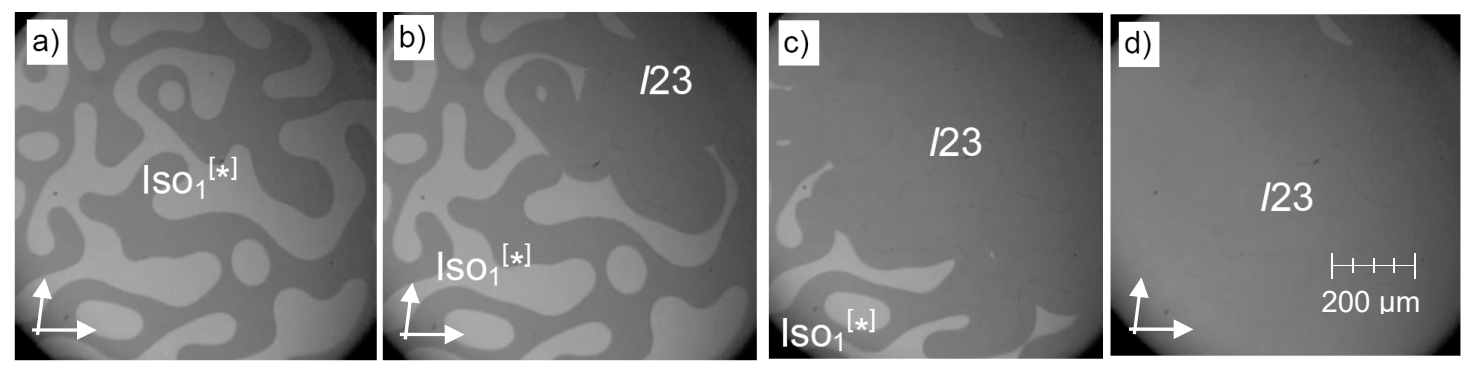

Figure 13. Spontaneous development of uniform chirality at the Iso ${ }^{[*]}$-to-Cub $\mathrm{bi}_{\mathrm{bi}} /[23$ transition, shown for compound $3(m=n=10)$ and as observed under a polarizing microscope at $T=175{ }^{\circ} \mathrm{C}$ (orientation of the polarizers is indicated by arrows), depending on time; (a) shows the Iso ${ }^{[*]}$ phase at $t=0 \mathrm{~s}$; (b) formation of the $I 23$ phase starts in the dark region at the top right, (c) the $I 23$ phase area grows towards the bottom left and (d) covers the complete area of view after $<10 \mathrm{~s}$; note that the optical rotatory power does not change at this transition, meaning that the local structure in the Iso ${ }^{[*]}$ phase is likely to be the same as in I23; see also the video associated as supporting material to [26].

\section{6. $C u b_{b i} / I 23$ Phase-Assisted Total Mirror Symmetry Breaking in Isotropic Liquids}

In some cases, it was observed that the formed Iso ${ }^{[*]}$ phase occurring beside the chiral cubic 123 phase is spontaneously shifted to one chirality, even in the absence of any chiral field (Figure 10c). This observation results from two different effects. First, the formation of the chiral cubic I23 phase may tend easily towards an imbalance of left- and right-handed domains, in most cases only slightly, but sometimes almost completely, as shown in Figure 13d, which creates a chiral field for the developing $\mathrm{Iso}^{[*]}$ phase. The other effect is the storage of the chiral information in the liquid state. It appears that the chiral information once gained in the I23 phase is stored either in clusters of networks persisting in the isotropic liquid phase range close to the Iso $^{[*]}$-Iso phase transition temperature, or in thin films at the surfaces. This range of the achiral isotropic liquid phase with a local network structure is designated here as Iso $_{1}$. The chiral memory is completely lost within few minutes in the achiral Iso phase at $>20 \mathrm{~K}$ above the phase transition and in this case upon cooling the racemic conglomerate composed of equal areas of the chiral domains is formed again. As the temperature difference to the Iso $^{[*]}-$ Iso $_{1}$ phase transition is reduced, the time required for complete loss of chiral memory increases. Even in a certain temperature range of the achiral isotropic liquid phase close to the $\mathrm{Iso}^{[*]}{ }_{-} \mathrm{Iso}_{1}$ transition, the chirality is memorized, so that, on cooling back to Iso ${ }^{[*]}$, either a uniformly chiral Iso ${ }^{[*]}$ phase is formed again or an equal or non-equal distribution of left and right domains is found. The outcome depends on the temperature difference to the $\mathrm{Iso}^{[*]}-\mathrm{Iso}_{1}$ phase transition temperature and on the time; it is kept at that temperature in the achiral Iso $_{1}$-phase. In this way, the interaction of the spontaneous formed chiral cubic phase with a ratio of left- and right-handed domains unequal the racemic 1:1 state, and memorizing this chiral information in the liquid state, generates a chiral field which easily leads to symmetry breaking over larger areas, or maybe total mirror symmetry breaking if the cycle $\mathrm{Cub}_{\mathrm{bi}} / \mathrm{I}_{23}-\mathrm{Iso}_{1}-\mathrm{Iso}^{[*]}$ is repeated.

\subsection{Complete Mirror Symmetry Breaking in Isotropic Liquds Due to Compartmentalization}

Another interesting observation made in the Iso ${ }^{[*]}$ phases is that impurities accumulate at the racemic interfaces between the chiral domains with opposite chirality, as shown in Figure 14; in this case as a result of thermal decomposition in the Iso ${ }^{[*]}$ phase at high temperatures. In the example shown in Figure 14a, the "membranes" enclosing the domains with opposite chirality are stable and the content retains uniform chirality in the liquid state. However, the "membranes" are not sufficiently stable to resist the chirality synchronization taking place across these boundaries at the phase transition to the cubic $I 23$ phase. Therefore, the boundaries between the chiral domains are shifted, whereas the position of the walls between the compartments does not change (most probably due to their pinning to the surfaces), and thus the formed "membranes" become visible as thin lines 
in the $\mathrm{Cub}_{\mathrm{bi}} / I 23$ phase (arrow in Figure $14 \mathrm{~b}, \mathrm{c}$ ). This could be considered as another alternative way for the transition from local to total mirror symmetry breaking in the Iso ${ }^{[*]}$ phase, in this case by isolating the domains with opposite chirality from each other, i.e., by reducing the length scale of the considered system, simply by enclosing and separating the different domains. It could be expected that the addition of properly chosen molecules, which are incompatible with the material forming the bulk Iso ${ }^{[*]}$ phase, can lead to more stable membranes, making the compartments more resistant to external influences. This provides an interesting mode of symmetry breaking, combining local symmetry breaking with compartmentalization in a single unified process. This could be a possible mechanism of the development of uniform chirality in abiogenesis, as discussed further below.
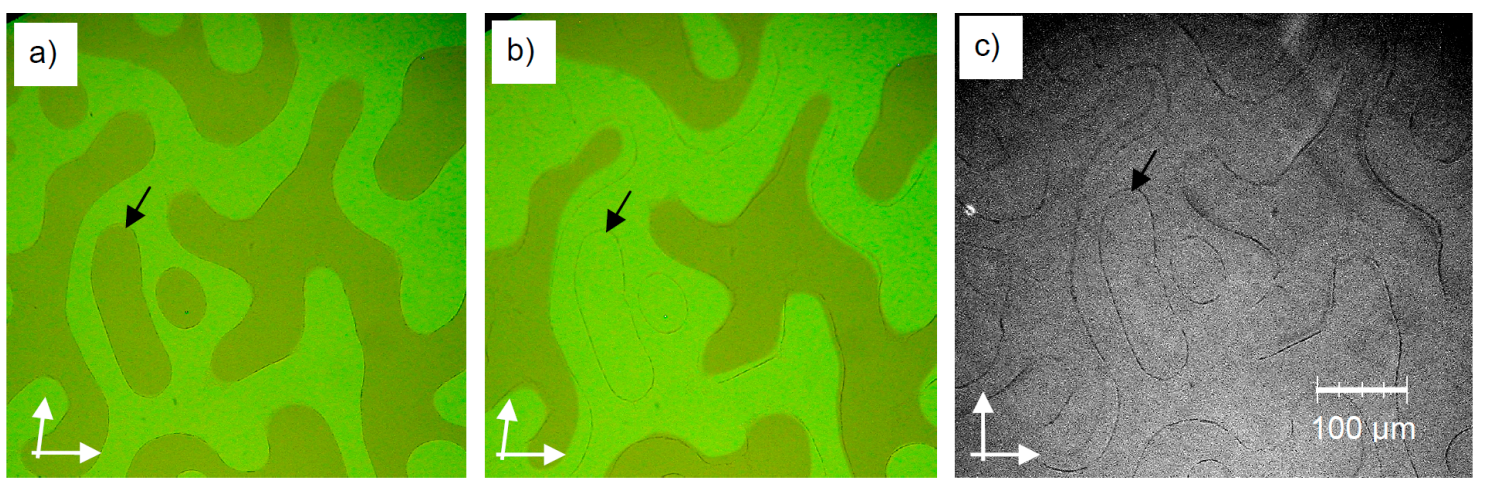

Figure 14. Compartmentalization by mirror symmetry breaking. (a) Chiral domains in the Iso ${ }^{[*]}$ phase of compound $3(m, n=10)$ at $T=177^{\circ} \mathrm{C}$. After annealing at this temperature for about an hour thermal decomposition products accumulate at the racemic walls between the domains with opposite chirality; (b) shows the same range after transition to the $\mathrm{Cub}_{\mathrm{bi}} / I 23$ phase upon cooling to $T=175^{\circ} \mathrm{C}$. Because of the slow seed formation, the borders between the chiral domains are shifted and the walls separating the chiral domains become visible. In this case, the walls are obviously not defect-free, meaning that they can still be passed by the chiral information. (c) shows (b) with crossed polarizers, and enlarges exposure time (previously unpublished results).

\subsection{Impact of Network Formation on Mirror Symmetry Breaking in Isotropic Liquids}

What is the origin of chirality in these liquids? These liquids occur, in most cases adjacent to one of the $\mathrm{Cub}_{\text {bi }}$ phases with helical network structure, either the achiral Ia3d or the mirror symmetry broken I23 phase. Therefore, it is likely that in the liquid state fragments of these, $\mathrm{Cub}_{\mathrm{bi}}$ phases are also retained as local clusters, leading to a liquid polyamorphism [142,143]. As shown in Figure 15 for the example of the benzil derivative 10 (Figure $6, n=12$ ) with the Iso ${ }^{[*]}$ phase occurring besides a Ia3d phase, the development of this cubic phase takes place from the isotropic liquid state by a series of phase transitions. These are indicated by three distinct exotherms in the DSC cooling traces, one dominating broad feature and two sharper transitions with smaller peaks [130] which can be interpreted as follows. With lowering temperature, nucleation of the molecules sets in, thus leading to clusters (cybotaxis), which increase in size. This clustering is supported by the nanoscale segregation of incompatible molecular parts, the rigid polyaromatic cores and the flexible alkyl chains [93,97,117], leading to short helix fragments. With further lowering temperature, the helical clusters grow and become interconnected to dynamic random networks (Figure 15b), which further grow and increase in connectivity in the range of the broad feature in the DSC trace (as introduced in Section 5.6, we designate this achiral liquid with a local network structure as Iso $_{1}$, see Figure 15a) [144]. At a certain critical connectivity, the helix sense is spontaneously synchronized over macroscopic distances, leading to the mirror symmetry broken liquid (Iso ${ }^{[*]}$ phase) $[25,130]$. The relatively sharp peak for this Iso $1^{-I_{s o}}{ }^{[*]}$ transition (Figure 15a) is likely to be mainly the result of the chiral segregation at this transition [25]. Further increasing network connectivity finally leads to the phase transition to the Cub $\mathrm{b}_{\mathrm{bi}}$ phase, where a long-range positional order is established $[40,130]$. 
a)
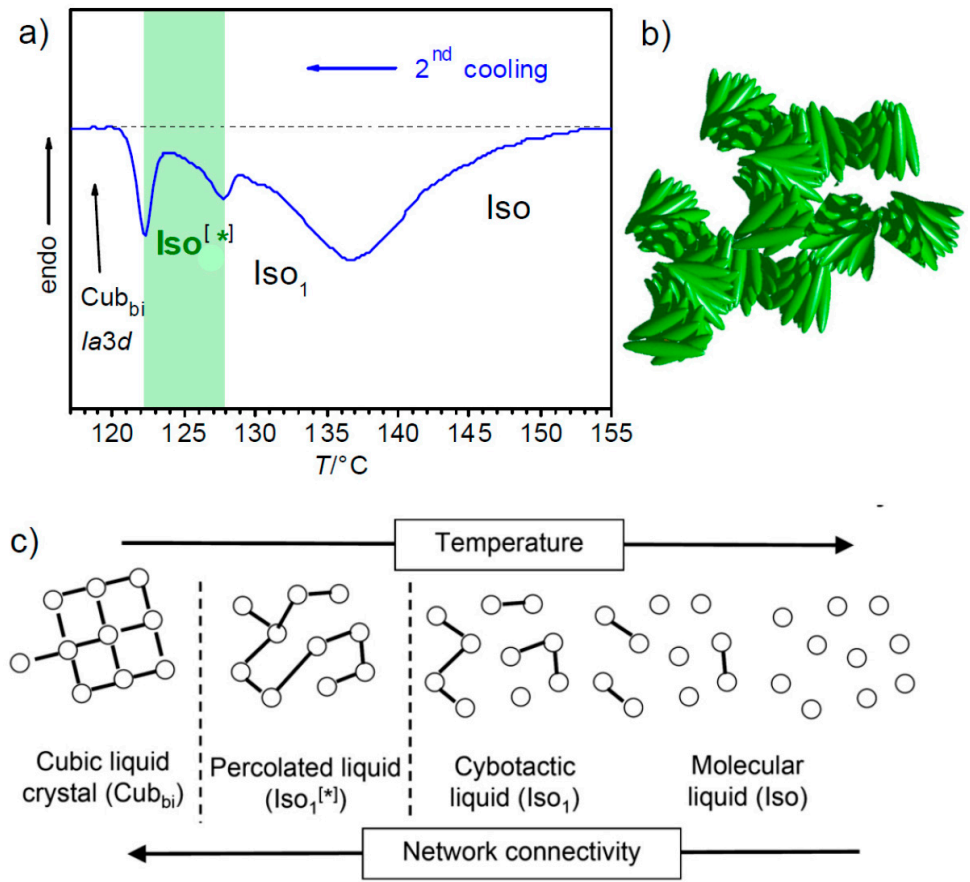

Figure 15. Investigation of the benzil compound 10 (Figure $6, n=12)$. (a) DSC cooling trace $\left(10 \mathrm{~K} \mathrm{~min}^{-1}\right.$ ) showing the transitions Iso-Iso $1-\mathrm{Iso}^{[*]}-\mathrm{Cub}_{\mathrm{bi}} / I_{a 3 d}$; (b) shows a model of the rod-like molecules in the dynamic helical networks of the Iso ${ }^{[*]}$ phase and (c) shows schematically the transition from an ordinary liquid via cybotactic and percolated network liquids to the $\mathrm{Cub}_{\mathrm{bi}}$ phase with increasing network connectivity $[40,42,130]$; the dots symbolize the helical nano-clusters and the lines the interactions between them. It is noted that the Iso-Iso 1 transition cannot be identified in the DSC traces as a separate phase transition in all cases, either if this transition is completely continuous or if the aggregate structure of the liquid is present in the whole achiral Iso range. This case is found for compounds 3 with a diphenyl-dithiophene core unit [25]; reprinted from [130].

Depending on the type of formed cubic lattice in the resulting cubic phase, the chirality of the Iso ${ }^{[*]}$ phases is either retained at the transition to the chiral $I 23$ phase or removed at the transition to the achiral Ia3d phase [26]. As the Iso ${ }^{[*]}-I a 3 d$ transition requires helix reversal for half of the molecules, this transition is slow and can be significantly supercooled compared to the transition on heating [137]. The whole sequence is shown schematically in Figure 15c, where the dots represent the local domains and the lines indicate their increasing connectivity to a network structure. Thus, the chirality synchronization and mirror symmetry breaking are supported by the presence of a dynamic network structure, even in the liquid state (percolated liquids, network liquids) [145-148]. The local structure of the networks in the Iso ${ }^{[*]}$ phase could either be completely random or I23-like, but not Ia3d-like, which would retain an achiral liquid state. There is no visible change in the optical rotation at the Iso ${ }^{[*]}-I 23$ transition (Figures 13 and 14 ), and therefore we can assume that the local structure is $I 23-$ like also in the Iso ${ }^{[*]}$ phase and that segregation of the helicity is complete in both phases, i.e., there should be uniform helix sense in the domains of these C-type systems. It is much more difficult to answer the question of the molecular helicity $[25,40,42]$. The compounds discussed here have no stereogenic centre, and hence are achiral. Nevertheless, these molecules can assume chiral conformations (see for example Figure 9a,b) [25,42]. Because the energy barrier between these conformers is relatively small, there is a conformational equilibrium of the enantiomorphic helices and this equilibrium is biased to some extent by the helical organization of the molecules towards one of the enantiomorphic conformers, leading to the energy minimum diastereomeric pair. Moreover, a denser packing is obviously achieved for conformers with uniform chirality and this effect is strengthened and long-range transmitted by the organization of the molecules in networks. Although we are sure about 
the homochirality of the helical networks, the degree of segregation of enantiomorphic conformers in these networks is more difficult to estimate and likely to be scalemic.

This raises the important question of if transient molecular chirality is required for helix formation, or if helix formation in liquids would be possible even without any contribution of molecular helicity. This is difficult to prove experimentally, because completely rigid polyaromatic units tend to crystallize instead of forming Iso ${ }^{[*]}$ phases. Nevertheless, this work has shown that, in C-type systems, chirality can spontaneously develop from achiral molecules as thermodynamically stable phases, even in the liquid or liquid crystalline state.

\section{Possible Scenario for Chirogenesis Based on Mirror Symmetry Breaking in Network Liquids}

Though it is self-evident that the reported system cannot have played any role in abiogenesis, this observation shows that chirality can arise spontaneously by liquid state self-assembly, just like the Soai reaction, which confirmed the concept of autocatalysis for the emergence of uniform chirality in autocatalytic cycles of chemical reactions [57,58]. The chirality develops under thermodynamic control, meaning that it is long-term stable and can be retained without the requirement of complex catalytic cycles. It allows the development of spontaneous chirality in liquids, even at the temperatures of hydrothermal vents, where abiogenesis is assumed to have started $[149,150]$. As shown above, the Iso ${ }^{[*]}$ phase is not restricted to local mirror symmetry breaking, but can also develop total mirror symmetry breaking either (i) stochastically by cycling across phase transitions or (ii) by compartmentalization, or (iii) deterministic under the influence of extremely weak chiral fields by chirality amplification. Toxvaerd proposed different chirogenesis scenarios of mirror symmetry breaking in fluids based on developing carbohydrate [19] and protein chirality [151]. However, we have shown that it works even with achiral molecules [25]. The only requirements are a C-type system, a rapid enantiomerization and network formation in a fluid system $[26,40,129]$. This raises the question of whether a related process of chirality synchronization in the liquid state could have been of importance for the emergence of homochirality during abiogenesis.

A possible hypothesis could be the following. If one believes the RNA world picture of the origin of life [152-154] and that chirality had to be selected before biogenesis, then homochirality perhaps developed together with the formation of early forms of RNA (proto-RNA or pre-RNA) [155,156]. As nowadays, prebiotically plausible ways towards nucloetides are known [4,154,157-159], the process could have started with the self-assembly of a library of these amphiphilic $N$-containing heteroaromatic compounds, forming (slightly twisted) hydrogen-bonded pairs or oligomers, stacking with their faces on top of each other (as still found in today's RNA and DNA). The dense packing expels the water from the core region, thus forming nano-segregated rods of helically twisted $\pi$-stacked $N$-heterocycles in the aqueous continuum (Figure 16a). With increasing concentrations of these short helices, they fuse to dynamic networks with long-range synchronized helicity, thus forming a mirror symmetry broken liquid (or a mirror symmetry broken $\mathrm{Cub}_{\mathrm{bi}}$ liquid crystal at an even higher concentration, Figure 16b). The polar groups, together with excess water, form the continuum in a very similar way to the alkyl chains in the case of the previously discussed polycatenars compounds. This helical organization might not only be driven by the different size of aromatic units and polar surrounding (Figure 8c), but also by the well-known tendency of staggered packing of these flat, electron-poor $N$-heterocycles [160-162]. 


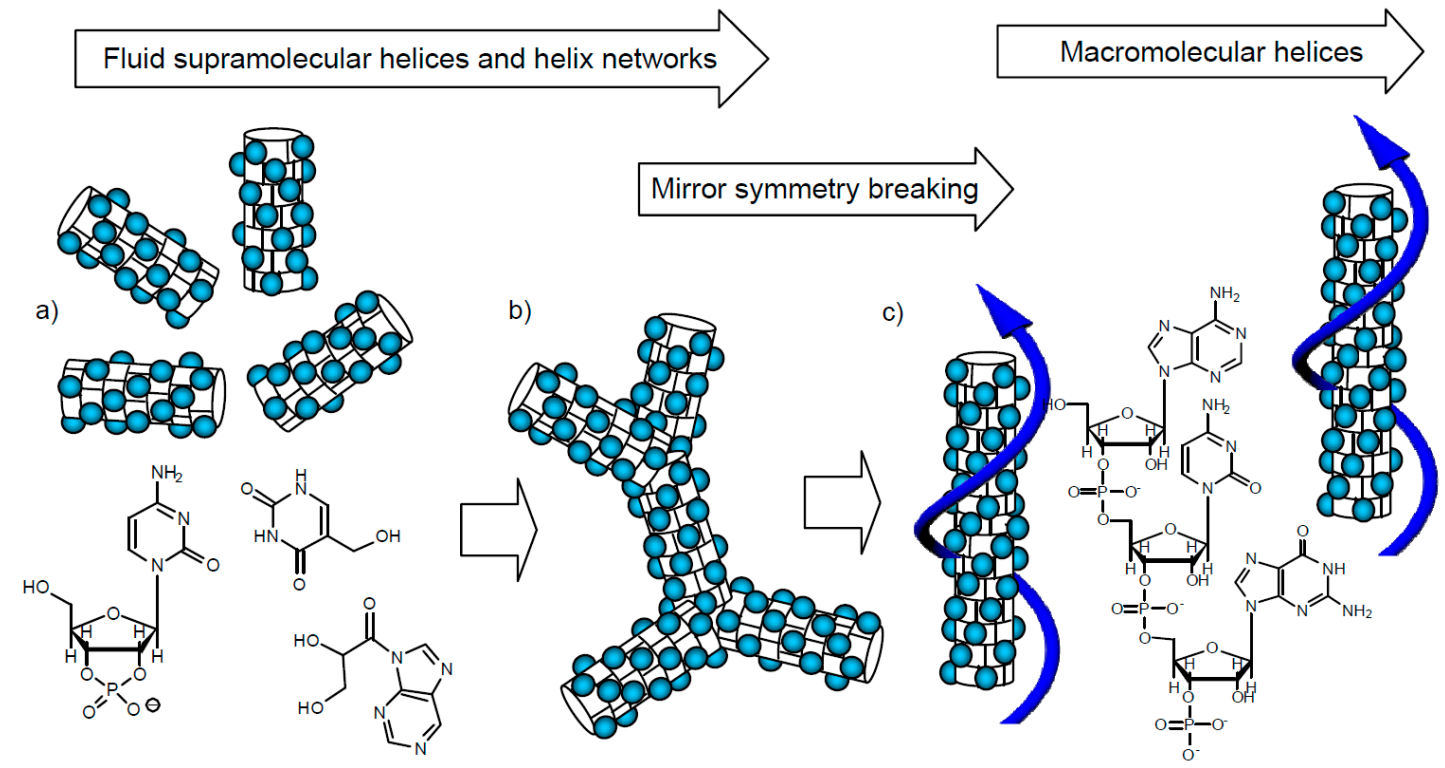

Dynamic helicity $\rightarrow$ Dynamic molecular chirality $\rightarrow$ Fixed helicity and molecular chirality

Figure 16. Hypothesis of development of biochirality: (a) Libraries of amphiphilic $N$-heterocycles self-assemble into dynamic helices (the blue dots represent the polar groups, being carbohydrates or other units) which (b) become chirality synchronized by dynamic network formation in the mirror symmetry broken helical network fluid and (c) polymerization leads to proto-RNA with fixed helicity and uniform absolute configuration (chirality) of the attached carbohydrates.

Thus, the helical self-assembly is determined by the achiral $N$-heterocyclic units, whereas the attached polar units are either achiral or (almost or completely) racemic and have no effect on the helix formation itself. The actual sense of helicity of these dynamic aggregates is either determined by local fluctuations (stochastic outcome) or by any kind of weak chiral field, leading to a deterministic outcome with preference for one sense of chirality. During growth of the dynamic helical networks, the building blocks were continuously exchanged to achieve the most stable helical system. This also includes the exchange of the wrong enantiomers. The formation of covalent bonds between properly preorganized groups in the polar periphery fixes the helical structure and leads to the development of dynamic proto-RNA oligomers (Figure 16c), in which the exchange and optimization continues due to the dynamics resulting from ongoing hydrolysis/condensation reactions as well as epimerization and racemization (transition from dynamic supramolecular aggregates to dynamic covalent bonds). The helix sense and also the once-chosen chirality of the carbohydrates or carbohydrate-like units (i.e., their relative and absolute configuration) become more and more fixed by the confinement provided by fixation in the developing polymer system [82,163-169]. Thus, the chirality synchronization is followed by covalent fixation. After reaching a critical polymer stability and after reaching a certain limiting polymer length, the interconnected network structure has to be given up, and from that point on, the helical proto-RNA can act as a relatively persistent carrier of the once-established chiral information (transition from dynamic to permanent covalent bonds). This would mean that uniform chirality is likely to have co-evolved during proto-RNA formation, which has fixed the carbohydrate chirality.

That chirality synchronization can indeed be observed in self-assembled soft matter systems formed by simple achiral amphiphilic $N$-heterocycles was recently shown experimentally for compound 11 (Figure 17) [170], where the oligoethylene glycol chain represents the polar group, replacing the ribose and phosphate units of the related nucleic acids. In the investigated case, it forms a glassy conglomerate of chiral domains in the bulk state (without solvent), as shown in Figure 17a,b [170]. The spontaneous formation of homochiral domains was recently also observed in supramolecular 
polymer gels formed in aqueous systems of self-assembled helical aggregates of hydrogen-bonded achiral heterocycles [171].
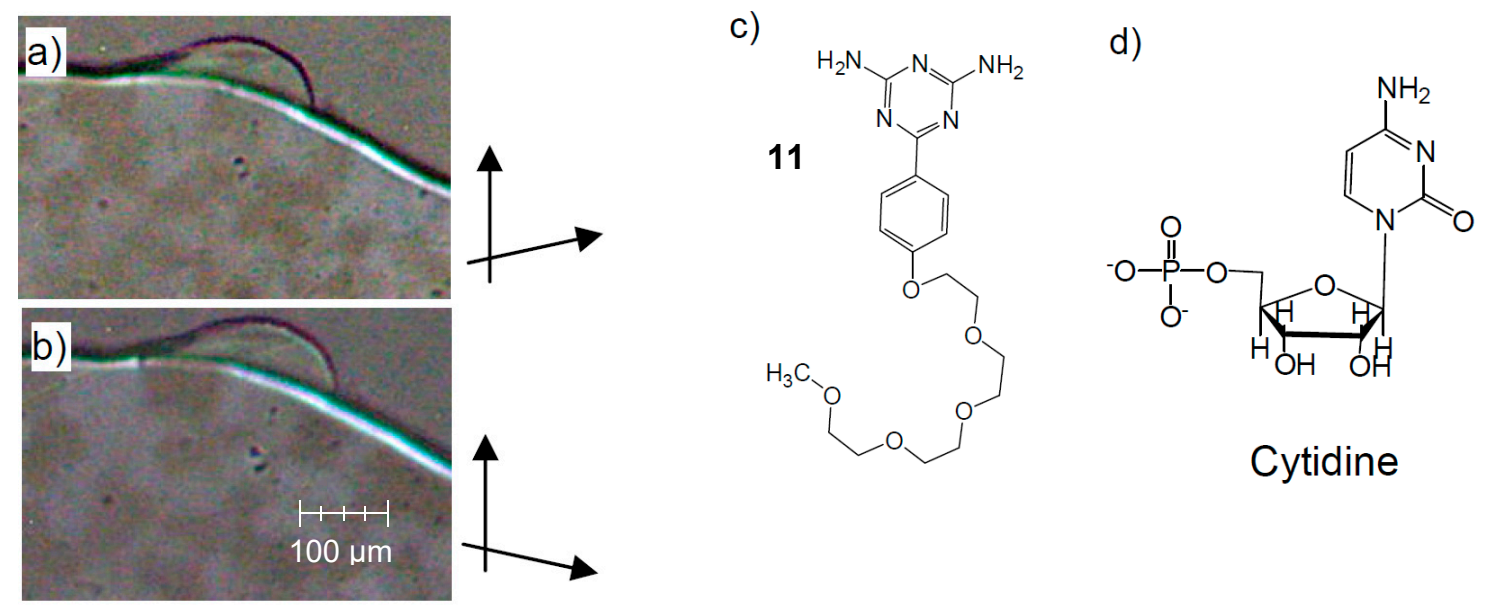

\section{Cytidine}

Figure 17. Amphiphilic $N$-heterocyclic compound 11 forming a glassy $\operatorname{Iso}^{[*]}$ phase. $(\mathbf{a}, \mathbf{b})$ show the chiral domains as observed between slightly uncrossed polarizers at $90^{\circ} \mathrm{C}$, (c) shows the molecular structure and (d) shows the structure of a nucleotide for comparison, adapted from [170].

Though peptides might have co-evolved together with RNA [82], peptide self-assembly itself is less likely to be the source of homochirality, though peptides are capable of helix formation and hydrophobic amino acids could give rise to amphiphilicity and aggregation [151], but they are unlikely to be able to form mirror symmetry broken liquid states. The reason for this is that for flexible amphiphiles (lipids [96], block-copolymers [101]), only double networks have been found to date, usually the achiral double-gyroid Ia3d phase. However, mirror symmetry breaking in network fluids requires a chiral network structure, as provided by the I23-like triple network, which has, to date, only been found for molecules involving sufficiently large $\pi$-conjugated aromatic units and this can be provided by the hydrogen-bonded pairs (or larger aggregates) of nucleobases and related $N$-heterocycles. This does not exclude that $N$-heterocycles of aromatic amino acids could also have been involved in the chirogenesis of network fluids and transferred their chirality to the developing peptides. This would be in line with a co-evolution scenario [81].

It is also likely that this chirogenesis process, which requires relatively high concentrations to retain the chirality synchronized fluid state, took place parallel in confined spaces like pores and with a different outcome in different pores. In larger spaces, the possibility of compartmentalization of the fluid conglomerates by developing walls formed by lipids and other lipophilic molecules accumulating at the racemic boundaries between the aqueous domains with opposite chirality would allow the coupled formation of protocells and uniform chirality. In both cases, the chirality is only selected within the individual compartments, and the overall outcome could still be racemic (stochastic), but one of the enantiomeric cell types can then become dominant in the following selection processes [5]. However, the huge chirality amplification power of the mirror symmetry broken network fluids [25] makes it more likely that the sign of chirality has developed in a more deterministic way under the influence of weak chirality fields (meteorites, chiral surfaces, circular polarized light, etc.) [9]. Once the dominating chirality sense is fixed, the weak chiral fields cannot alter the once selected chirality.

Thus, the early RNA could have not only acted as the first information carrier and catalyst, it might also have provided uniform biochirality. Accordingly, biochirality would have developed from achiral units, capable of forming dynamic helical networks by self-assembly into a chiral prebiotic fluid, and this triggered the formation of the biorelevant molecules which were homogeneously chiral (or at least scalemic) right from the beginning (see Figure 18). Thus, chirality can probably be considered as the first information stored by the emerging RNA. This model is only based on thermodynamic 
arguments, molecular self-assembly and phase transitions. It does not require complex chemical reaction networks, kinetically stabilized stationary states and a continuous flow of energy or material, and therefore is likely to be compatible with the situation at the very beginning of abiogenesis.

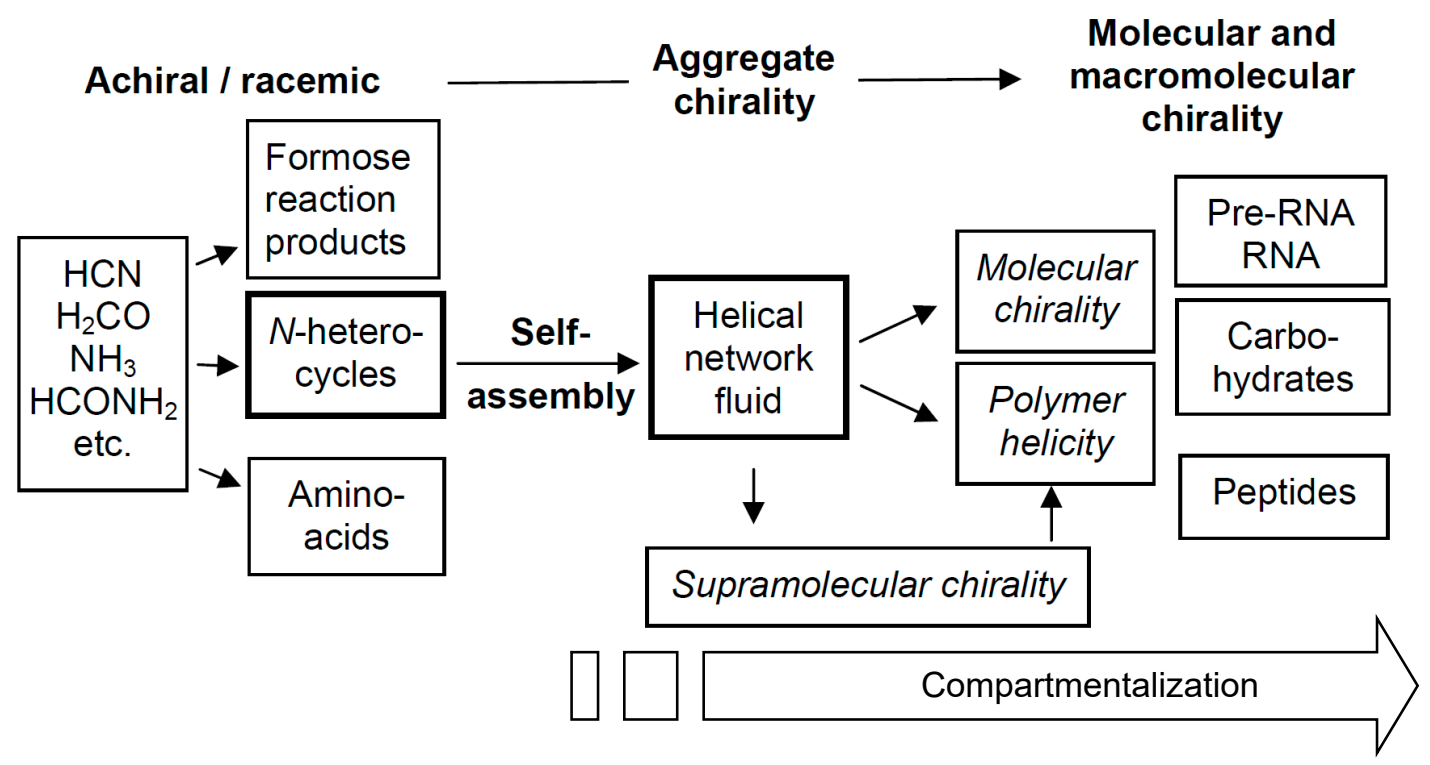

Figure 18. Scheme showing a possible transition from simple achiral to chiral molecules and complex functional biopolymers in abiogenesis, being mediated by chiral network fluids.

Overall, during abiogenesis, the complexity of chemical systems has increased by a combination of chemical reactions and self-assembly (molecular and supramolecular self-assembly). Abiogenesis presumably started with small achiral molecules $\left(\mathrm{HCN}, \mathrm{NH}_{3}, \mathrm{H}_{2} \mathrm{CO}\right.$, etc.) where chirality did not play a role. They condensed to larger molecules (heterocycles, formose reaction products and amino acids) where chirality became an issue. Some of these molecules were capable of soft helical self-assembly, forming fluid networks capable of chirality synchronization. The developing uniform chirality then allowed the formation of polymers and the fixation of the selected chirality sense, and homochiral molecules and polymers were formed. The emerging molecular homochirality then triggered the transition from simple chemistry to complex reaction networks and catalytic and autocatalytic metabolic cycles, which gave rise to non-equilibrium chemistry in abiogenesis (transition from self-assembly to self-organization), finally leading to the Darwinistic evolution of life in the continuing biogenesis.

\section{Conclusions}

Recent progress in mirror symmetry breaking and chirality amplification in isotropic liquids and liquid crystalline cubic phases of achiral molecule is reviewed and discussed in relation to the autocatalytic Soai chirality amplification reaction, the Viedma type deracemizations, and with respect to its implications for the hypothesis of emergence of biological chirality. It is shown that this symmetry breaking process requires fluid systems where homochiral interactions are preferred over heterochiral (C-type systems). Moreover, it is experimentally shown that dynamic network structures lead to chirality synchronization if the enantiomerization barrier is sufficiently low, i.e., that racemization drives the development of uniform chirality. The typical outcome is conglomerate formation, indicating a local mirror symmetry breaking. This led to the first experimentally proven example of phase separation in an isotropic liquid solely based on mirror symmetry breaking. Total mirror symmetry breaking was found by crossing phase transitions due to kinetic effects, or under the influence of minor chiral fields, leading to stochastic and deterministic homochirality, respectively. This is associated with the extreme chirality amplification power of these systems, especially close to the bifurcation point. Once formed, these mirror symmetry broken liquids are longtime stable because they represent thermodynamic 
minimum systems. This mode of spontaneous mirror symmetry breaking in the isotropic liquid state is considered as important for the emergence of biochirality. A model is hypothesized, which assumes the emergence of uniform chirality by dynamic helical networks in fluids formed by achiral heterocycles in water, followed by polymerization, which fixes chirality and simultaneously leads to (proto)-RNA formation and uniform biochirality. Possibly, this process was even combined with a liquid-liquid compartmentalization, providing a dynamic cellular structure.

Funding: Parts of this work were funded by the Deutsche Forschungsgemeinschaft, grant number Ts 39/24-2.

Conflicts of Interest: The authors declare no conflict of interest. The funders had no role in the design of the study; in the collection, analyses, or interpretation of data; in the writing of the manuscript, or in the decision to publish the results.

\section{References}

1. Pasteur, L. Recherches sur les relations qui peuvent exister entre la forme crystalline, la composition chimique et le sens de la polarisation rotatoire. Ann. Chim. Phys. 1848, 24, 442-459.

2. Palyi, G. Biological Chirality; Academic Press, Elsevier: London, UK, 2020.

3. Weiss, M.C.; Preiner, M.; Xavier, J.C.; Zimorski, V.; Martin, W.F. The last universal common ancestor between ancient Earth chemistry and the onset of Genetics. PLoS Genet. 2018, 14, e1007518. [CrossRef] [PubMed]

4. Islam, S.; Powner, M.W. Prebiotic Systems Chemistry: Complexity Overcoming Clutter. Chem 2017, 2, 470-501. [CrossRef]

5. Green, M.M.; Jain, V. Homochirality in Life: Two Equal Runners, One Tripped. Orig. Life Evol. Biosph. 2010, 40, 111-118. [CrossRef] [PubMed]

6. Walker, S.I. Origins of life: A problem for physics, a key issues review. Rep. Prog. Phys. 2017, 80, 092601. [CrossRef] [PubMed]

7. Ruiz-Mirazo, K.; Briones, C.; de la Escosura, A. Prebiotic Systems Chemistry: New Perspectives for the Origins of Life. Chem. Rev. 2014, 114, 285-366. [CrossRef] [PubMed]

8. Rauchfuss, H. Chemical Evolution and the Origin of Life; Springer: Berlin/Heidelberg, Germany, 2008.

9. Guijarro, A.; Yus, M. The Origin of Chirality in the Molecules of Life; RSC publishing: Cambridge, UK, 2009.

10. Luisi, P.L. The Emergence of Life; Cambridge University Press: Cambridge, UK, 2006.

11. Meierhenrich, U. Amino Acids and the Asymmetry of Life; Springer: Berlin/Heidelberg, Germany, 2008.

12. Cintas, P. Biochirality, Origins, Evolution and Molecular Recognition; Springer: Berlin/Heidelberg, Germany, 2013.

13. Cronin, J.; Reisse, J. Chirality and the Origin of Homochirality. In Lectures in Astrobiology; Gargaud, M., Barbier, B., Martin, H., Reise, J., Eds.; Springer: Berlin/Heidelberg, Germany, 2005; Volume 1, pp. 473-515.

14. Blackmond, D.G. The Origin of Biological Homochirality. Cold Spring Harb. Perspect. Biol. 2019, 11, a032540. [CrossRef] [PubMed]

15. Coveney, P.V.; Swadling, J.B.; Wattis, J.A.D.; Greenwell, H.C. Theory, modelling and simulation in origins of life studies. Chem. Soc. Rev. 2012, 41, 5430-5446. [CrossRef] [PubMed]

16. Ribo, J.M.; Hochberg, D.; Crusats, J.; El-Hachemi, Z.; Moyano, A. Spontaneous mirror symmetry breaking and origin of biological homochirality. J. R. Soc. Interface 2017, 14, 20170699. [CrossRef] [PubMed]

17. Ribó, J.M.; Hochberg, D. Chemical Basis of Biological Homochirality during the Abiotic Evolution Stages on Earth. Symmetry 2019, 11, 814. [CrossRef]

18. Pavlov, V.A.; Shushenachev, Y.V.; Zlotin, S.G. Chiral and Racemic Fields Concept for Understanding of the Homochirality Origin, Asymmetric Catalysis, Chiral Superstructure Formation from Achiral Molecules, and B-Z DNA Conformational Transition. Symmetry 2019, 11, 649. [CrossRef]

19. Toxvaerd, S. The Role of Carbohydrates at the Origin of Homochirality in Biosystems. Orig. Life Evol. Biosph. 2013, 43, 391-409. [CrossRef] [PubMed]

20. Toxvaerd, S. A Prerequisite for Life. J. Theor. Biol. 2019, 474, 48-51. [CrossRef] [PubMed]

21. Hein, J.E.; Blackmond, D.G. On the Origin of Single Chirality of Amino Acids and Sugars in Biogenesis. Acc. Chem. Res. 2012, 45, 2045-2054. [CrossRef]

22. Pavlov, V.A.; Klabunovskii, E.I. Homochirality Origin in Nature: Possible Versions. Curr. Org. Chem. 2014, 18, 93-114. [CrossRef] 
23. Avalos, M.; Babiano, R.; Cintas, P.; Jimenez, J.L.; Palacios, J.C. Homochirality and chemical evolution: New vistas and reflections on recent models. Tetrahedron Asymmetry 2010, 21, 1030-1040. [CrossRef]

24. Suzuki, N.; Itabashi, Y. Possible Roles of Amphiphilic Molecules in the Origin of Biological Homochirality. Symmetry 2019, 11, 966. [CrossRef]

25. Dressel, C.; Reppe, T.; Prehm, M.; Brautzsch, M.; Tschierske, C. Chiral self-sorting and amplification in isotropic liquids of achiral molecules. Nat. Chem. 2014, 6, 971-977. [CrossRef]

26. Dressel, C.; Liu, F.; Prehm, M.; Zeng, X.B.; Ungar, G.; Tschierske, C. Dynamic Mirror-Symmetry Breaking in Bicontinuous Cubic Phases. Angew. Chem. Int. Ed. 2014, 53, 13115-13120. [CrossRef]

27. Yashima, E.; Ousaka, N.; Taura, D.; Shimomura, K.; Ikai, T.; Maeda, K. Supramolecular helical systems: Helical assemblies of small molecules, foldamers, and polymers with chiral amplification and their functions. Chem. Rev. 2016, 116, 13752-13990. [CrossRef]

28. Liu, M.; Zhang, L.; Wang, T. Supramolecular chirality in self-assembled systems. Chem. Rev. 2015, 115, 7304-7397. [CrossRef]

29. Barclay, T.G.; Constantopoulos, K.; Matisons, J. Nanotubes self-assembled from amphiphilic molecules via helical intermediates. Chem. Rev. 2014, 114, 10217-10291. [CrossRef]

30. La, A.D.D.; Al Kobaisi, M.; Gupta, A.; Bhosale, S.V. Chiral Assembly of AIE-Active Achiral Molecules: An Odd Effect in Self-Assembly. Chem. Eur. J. 2017, 23, 3950-3956. [CrossRef]

31. Sang, Y.; Liu, M. Symmetry Breaking in Self-Assembled Nanoassemblies. Symmetry 2019, 11, 950. [CrossRef]

32. Changa, B.; Lib, X.; Suna, T. Self-assembled chiral materials from achiral components or racemates. Eur. Polym. J. 2019, 118, 365-381. [CrossRef]

33. Hoeben, F.J.M.; Jonkheijm, P.; Meijer, E.W.; Schenning, A.P.H.J. About Supramolecular Assemblies of $\pi$-Conjugated Systems. Chem. Rev. 2005, 105, 1491-1546. [CrossRef]

34. Palmans, A.R.A.; Meijer, E.W. Amplification of chirality in dynamic supramolecular Aggregates. Angew. Chem. Int. Ed. 2007, 46, 8948-8968. [CrossRef]

35. Zhang, L.; Wang, T.; Shen, Z.; Liu, M. Chiral Nanoarchitectonics: Towards the Design, Self-Assembly, and Function of Nanoscale Chiral Twists and Helices. Adv. Mater. 2016, 28, 1044-1059. [CrossRef]

36. Pijper, D.; Feringa, B.L. Control of dynamic helicity at the macro- and supramolecular level. Soft Matter 2008, 4, 1349-1372. [CrossRef]

37. Ariga, K.; Mori, T.; Kitao, T.; Uemura, T. Supramolecular Chiral Nanoarchitectonics. Adv. Mater. 2020, 1905657. [CrossRef]

38. De Greef, T.F.A.; Smulders, M.M.J.; Wolffs, M.; Schenning, A.P.H.J.; Sijbesma, R.P.; Meijer, E.W. Supramolecular polymerization. Chem. Rev. 2009, 109, 5687-5754. [CrossRef] [PubMed]

39. Lehmann, A.; Alaasar, M.; Poppe, M.; Poppe, S.; Prehm, M.; Nagaraj, M.; Sreenilayam, S.P.; Panarin, J.P.; Vij, J.K.; Tschierske, C. Stereochemical Rules Govern the Soft Self-Assembly of Achiral Compounds: Understanding the Heliconical Liquid-Crystalline Phases of Bent-Core Mesogens. Chem. Eur. J. 2020, 26, 4714-4733. [CrossRef] [PubMed]

40. Tschierske, C. Mirror symmetry breaking in liquids and liquid crystals. Liq. Cryst. 2018, 45, $2221-2252$. [CrossRef]

41. Le, K.V.; Takezoe, H.; Araoka, F. Chiral Superstructure mesophases of achiral bent-shaped molecules-hierarchical chirality amplification and physical properties. Adv. Mater. 2017, 29, 1602737. [CrossRef] [PubMed]

42. Tschierske, C.; Ungar, G. Mirror Symmetry Breaking by Chirality Synchronisation in Liquids and Liquid Crystals of Achiral Molecules. ChemPhysChem 2016, 17, 9-26. [CrossRef]

43. Dierking, I. Chiral Liquid Crystals: Structures, Phases, Effects. Symmetry 2014, 6, 444-472. [CrossRef]

44. Nishyiama, I. Remarkable Effect of Pre-organization on the Self Assembly in Chiral Liquid Crystals. Chem. Rec. 2010, 9, 340-355. [CrossRef] [PubMed]

45. Bisoyi, H.K.; Bunning, T.J.; Li, Q. Stimuli-Driven Control of the Helical Axis of Self-Organized Soft Helical Superstructures. Adv. Mater. 2018, 30, 1706512. [CrossRef]

46. Eliel, E.L.; Wilen, S.H.; Mander, L.N. Stereochemistry of Organic Compounds; Wiley: New York, NY, USA, 1994.

47. Jacques, J.; Collet, A.; Wilen, S.H. Enantiomers, Racemates and Resolutions; Wiley: New York, NY, USA, 1981.

48. Mills, W.H. Some Aspects of Stereochemistry. Chem. Ind. 1932, 51, 750-759. [CrossRef]

49. Morowitz, M. A mechanism for the amplification of fluctuations in racemic mixtures. J. Theor. Biol. 1969, 25, 491-494. [CrossRef] 
50. Siegel, J. Homochiral Imperative of Molecular Evolution. Chirality 1998, 10, 24-27. [CrossRef]

51. Lente, G. The Role of Stochastic Models in Interpreting the Origins of Biological Chirality. Symmetry 2010, 2, 767-798. [CrossRef]

52. Hochberg, D.; Zorzano, M.-P. Reaction-noise induced homochirality. Chem. Phys. Lett. 2006, 431, $185-189$. [CrossRef]

53. Kondepudi, D.K.; Aaskura, K. Chiral Autocatalysis, Spontaneous Symmetry Breaking, and Stochastic Behavior. Acc. Chem. Res. 2001, 34, 946-954. [CrossRef]

54. Silva-Dias, L.; Lopez-Castillo, A. Stochastic chiral symmetry breaking process besides the deterministic one. Phys. Chem. Chem. Phys. 2017, 19, 29424-29428. [CrossRef] [PubMed]

55. Frank, F.C. On spontaneous asymmetric synthesis. Biochim. Biophys. Acta 1953, 11, 459-464. [CrossRef]

56. Weissbuch, I.; Leiserowitz, L.; Lahav, M. Stochastic “Mirror Symmetry Breaking” via Self-Assembly, Reactivity and Amplification of Chirality: Relevance to Abiotic Conditions. Top. Curr. Chem. 2005, 259, 123-165. [CrossRef]

57. Soai, K.; Kawasaki, T.; Matsumoto, A. The Origins of Homochirality Examined by Using Asymmetric Autocatalysis. Chem. Rec. 2014, 14, 70-83. [CrossRef]

58. Soai, K.; Kawasaki, T.; Matsumoto, A. Role of Asymmetric Autocatalysis in the Elucidation of Origins of Homochirality of Organic Compounds. Symmetry 2019, 11, 694. [CrossRef]

59. Satyanarayana, T.; Abraham, S.; Kagan, H.B. Nonlinear Effects in Asymmetric Catalysis. Angew. Chem. Int. Ed. 2009, 48, 456-494. [CrossRef]

60. Kawasaki, T.; Tanaka, H.; Tsutsumi, T.; Kasahara, T.; Sato, I.; Soai, K. Chiral Discrimination of Cryptochiral Saturated Quaternary and Tertiary Hydrocarbons by Asymmetric Autocatalysis. J. Am. Chem. Soc. 2006, 128, 6032-6033. [CrossRef] [PubMed]

61. Kawasaki, T.; Okano, Y.; Suzuki, E.; Takano, S.; Oji, S.; Soai, K. Asymmetric Autocatalysis: Triggered by Chiral Isotopomer Arising from Oxygen Isotope Substitution. Angew. Chem. Int. Ed. 2011, 50, 8131-8133. [CrossRef] [PubMed]

62. Matsumoto, A.; Kaimori, Y.; Uchida, M.; Omori, H.; Kawasaki, T.; Soai, K. Achiral Inorganic Gypsum Acts as an Origin of Chirality through Its Enantiotopic Surface in Conjunction with Asymmetric Autocatalysis. Angew. Chem. Int. Ed. 2017, 56, 545-548. [CrossRef]

63. Soai, K.; Sato, I.; Shibata, T.; Komiya, S.; Hayashi, M.; Matsueda, Y.; Imamura, H.; Hayase, T.; Morioka, H.; Tabira, H.; et al. Asymmetric synthesis of pyrimidyl alkanol without adding chiral substances by the addition of diisopropylzinc to pyrimidine-5-carbaldehyde in conjunction with asymmetric autocatalysis. Tetrahedron Asymmetry 2003, 14, 185-188. [CrossRef]

64. Singleton, D.A.; Vo, L.K. A Few Molecules Can Control the Enantiomeric Outcome. Evidence Supporting Absolute Asymmetric Synthesis Using the Soai Asymmetric Autocatalysis. Org. Lett. 2003, 5, 4337-4339. [CrossRef]

65. Toxvaerd, S. Origin of homochirallity in biosystems. Int. J. Mol. Sci. 2009, 10, 1290-1299. [CrossRef] [PubMed]

66. Plasson, R.; Kondepudi, D.K.; Bersine, H.; Commeyras, A.; Asakura, K. Emergence of Homochirality in Far-From-Equilibrium Systems: Mechanisms and Role in Prebiotic Chemistry. Chirality 2007, 19, 589-600. [CrossRef] [PubMed]

67. Ribo, J.M.; Blanco, C.; Crusats, J.; El-Hachemi, Z.; Hochberg, D.; Moyano, A. Absolute Asymmetric Synthesis in Enantioselective Autocatalytic Reaction Networks: Theoretical Games, Speculations on Chemical Evolution and Perhaps a Synthetic Option. Chem. Eur. J. 2014, 20, 17250-17271. [CrossRef]

68. Toxvaerd, S. Molecular Dynamics Simulations in Isomerization Kinetics in Condensed Fluids. Phys. Rev. Lett. 2000, 85, 4747-4750.

69. Jafarpour, F.; Biancalani, T.; Goldenfeld, N. Noise-induced symmetry breaking far from equilibrium and the emergence of biological homochirality. Phys. Rev. E 2017, 95, 032407. [CrossRef]

70. Sugimori, T.; Hyuga, H.; Saito, Y. Fluctuation Induced Homochirality. J. Phys. Soc. Jpn. 2008, 77, 064606. [CrossRef]

71. Latinwo, F.; Stillinger, F.H.; Debenedetti, P.G. Molecular model for chirality phenomena. J. Chem. Phys. 2016, 145, 154503. [CrossRef]

72. Brandenburg, A. The Limited Roles of Autocatalysis and Enantiomeric Cross-Inhibition in Achieving Homochirality in Dilute Systems. Orig. Life Evol. Biosph. 2019, 49, 49-60. [CrossRef] 
73. Kondepudi, D.K.; Kaufman, R.J.; Singh, N. Chiral Symmetry Breaking in Sodium Chlorate Crystallizaton. Science 1990, 250, 975-976. [CrossRef] [PubMed]

74. Viedma, C. Chiral Symmetry Breaking During Crystallization: Complete Chiral PurityInduced by Nonlinear Autocatalysis and Recycling. Phys. Rev. Lett. 2005, 94, 065504. [CrossRef] [PubMed]

75. Cintas, P.; Viedma, C. On the Physical Basis of Asymmetry and Homochirality. Chirality 2012, 24, 894-898. [CrossRef] [PubMed]

76. Blackmond, D.G. "Chiral Amnesia” as a Driving Force for Solid-Phase Homochirality. Chem. Eur. J. 2007, 13, 3290-3295. [CrossRef]

77. Noorduin, W.L.; Vlieg, E.; Kellogg, R.M.; Kaptein, B. From Ostwald Ripening to Single Chirality. Angew. Chem. Int. Ed. 2009, 48, 9600-9606. [CrossRef]

78. Amabilino, D.B.; Kellogg, R.M. Spontaneous Deracemization. Isr. J. Chem. 2011, 51, 1034-1040. [CrossRef]

79. Uemura, N.; Sano, K.; Matsumoto, A.; Yoshida, Y.; Mino, T.; Sakamoto, M. Absolute Asymmetric Synthesis of an Aspartic Acid Derivative from Prochiral Maleic Acid and Pyridine under Achiral Conditions. Chem. Asian J. 2019, 14, 4150-4153. [CrossRef]

80. Tsogoeva, S.B.; Wei, S.; Freund, M.; Mauksch, M. Generation of Highly Enantioenriched Crystalline Products in Reversible Asymmetric Reactions with Racemic or Achiral Catalysts. Angew. Chem. Int. Ed. 2009, 48, 590-594. [CrossRef] [PubMed]

81. McLaughlin, D.T.; Thao Nguyen, T.P.; Mengnjo, L.; Bian, C.; Leung, Y.H.; Goodfellow, E.; Ramrup, P.; Woo, S.; Cuccia, L.A. Viedma Ripening of Conglomerate Crystals of Achiral Molecules Monitored Using Solid-State Circular Dichroism. Cryst. Growth Des. 2014, 14, 1067-1076. [CrossRef]

82. Runnels, C.M.; Lanier, K.A.; Williams, J.K.; Bowman, J.C.; Petrov, A.S.; Hud, N.V.; Williams, L.D. Folding, Assembly, and Persistence: The Essential Nature and Origins of Biopolymers. J. Mol. Evol. 2018, 86, 598-610. [CrossRef] [PubMed]

83. Kenney, J.F.; Deiters, U.K. The evolution of multicomponent systems at high pressures Part IV. The genesis of optical activity in high-density, abiotic Nuids. Phys. Chem. Chem. Phys. 2000, 2, 3163-3174. [CrossRef]

84. Hochberg, D.; Cintas, P. Does Pressure Break Mirror-Image Symmetry? A Perspective and New Insights. ChemPhysChem 2020, 21, 633-642. [CrossRef] [PubMed]

85. Leporl, L.; Mengherl, M.; Molllca, V. Discriminating Interactions between Chiral Molecules in the Liquid Phase: Effect on Volumetric Properties. J. Phys. Chem. 1983, 87, 3520-3525. [CrossRef]

86. Atik, Z.; Ewing, M.B.; McGlashan, M.L. Chiral Discrimination in Liquids. Excess Molar Volumes of $(1-\mathrm{x}) \mathrm{A}++\mathrm{xA}$, Where A Denotes Limonene, Fenchone, and a-Methylbenzylamine. J. Phys. Chem. 1981, 85, 3300-3303. [CrossRef]

87. Dressel, C.; Weissflog, W.; Tschierske, C. Spontaneous mirror symmetry breaking in a re-entrant isotropic liquid. Chem. Commun. 2015, 51, 15850-15853. [CrossRef]

88. Alaasar, M.; Poppe, S.; Dong, Q.; Liu, F.; Tschierske, C. Mirror symmetry breaking in cubic phases and isotropic liquids driven by hydrogen bonding. Chem. Commun. 2016, 52, 13869-13872. [CrossRef]

89. Alaasar, M.; Prehm, M.; Cao, Y.; Liu, F.; Tschierske, C. Spontaneous Mirror-Symmetry Breaking in Isotropic Liquid Phases of Photoisomerizable Achiral Molecules. Angew. Chem. Int. Ed. 2016, 55, 312-316. [CrossRef] [PubMed]

90. Alaasar, M.; Poppe, S.; Dong, Q.; Liu, F.; Tschierske, C. Isothermal Chirality Switching in Liquid-Crystalline Azobenzene Compounds with Non Polarized Light. Angew. Chem. Int. Ed. 2017, 56, 10801-10805. [CrossRef]

91. Goodby, J.W.; Collings, P.J.; Kato, T.; Tschierske, C.; Gleeson, H.F.; Raynes, P. Handbook of Liquid Crystals, 2nd ed; Wiley-VHC: Weinheim, Germany, 2014.

92. Kato, T.; Uchida, J.; Ichikawa, T.; Sakamoto, T. Functional Liquid Crystals towards the Next Generation of Materials. Angew. Chem. Int. Ed. 2018, 57, 4355-4371. [CrossRef]

93. Tschierske, C. Development of Structural Complexity by Liquid-Crystal Self-assembly. Angew. Chem. Int. Ed. 2013, 52, 8828-8878. [CrossRef]

94. Mitov, M. Cholesteric liquid crystals in living matter. Soft Matter 2017, 13, 4176-4209. [CrossRef] [PubMed]

95. Lynch, M.L.; Spicer, P.T. (Eds.) Bicontinuous Liquid Crystals; Surfactant Science Series 127; CRC Press-Taylor \& Francis Group: Boca Raton, FL, USA, 2005.

96. Seddon, J.M.; Templer, R.H. Polymorphism of Lipid-Water Systems. In Handbook of Biological Physics; Lipowsky, R., Sackmann, E., Eds.; Elsevier: Amsterdam, the Netherlands, 1995; Volume 1, pp. 97-160. 
97. Tschierske, C. Micro-segregation, molecular shape and molecular topology-Partners for the design of liquid crystalline materials with complex mesophase morphologies. J. Mater. Chem. 2001, 11, 2647-2671. [CrossRef]

98. Borisch, K.; Diele, S.; Göring, P.; Kresse, H.; Tschierske, C. Tailoring Thermotropic Cubic Mesophases: Amphiphilic Polyhydroxy Derivatives. J. Mater. Chem. 1998, 8, 529-543. [CrossRef]

99. Kutsumizu, S. Recent Progress in the Synthesis and Structural Clarification of Thermotropic Cubic Phases. Isr. J. Chem. 2012, 52, 844-853. [CrossRef]

100. Ungar, G.; Liu, F.; Zeng, X. Cubic and 3D Thermotropic Liquid Crystal Phases and Quasicrystals. In Handbook of Liquid Crystals, 2nd ed; Goodby, J.W., Collings, P.J., Kato, T., Tschierske, C., Gleeson, H.F., Raynes, P., Eds.; Wiley-VHC: Weinheim, Germany, 2014; Volume 5, pp. 363-436.

101. Meuler, A.J.; Hillmyer, M.A.; Bates, F.S. Ordered Network Mesostructures in Block Polymer Materials. Macromolecules 2009, 42, 7221-7250. [CrossRef]

102. Hyde, S.; Andersson, S.; Larsson, K.; Blum, Z.; Landh, T.; Lidin, S.; Ninham, B.W. The Language of Shape, The Role of Curvature in Condensed Matter: Physics, Chemistry and Biology; Elsevier: Amsterdam, The Netherlands, 1997.

103. Deamer, D. Liquid crystalline nanostructures: Organizing matrices for non-enzymatic nucleic acid polymerization. Chem. Soc. Rev. 2012, 41, 5375-5379. [CrossRef] [PubMed]

104. Hamley, I.W. Liquid crystal phase formation by biopolymers. Soft Matter 2010, 6, 1863-1871. [CrossRef]

105. Jewell, S.A. Living systems and liquid crystals. Liq. Cryst. 2011, 38, 1699-1714. [CrossRef]

106. Steward, G.T. Liquid crystals in biology II. Origins and processes of life. Liq. Cryst. 2004, 31, $443-471$. [CrossRef]

107. Rey, A.D. Liquid crystal models of biological materials and processes. Soft Matter 2010, 6, 3402-3429. [CrossRef]

108. Giraud-Guille, M.M.; Belamie, E.; Mosser, G.; Helary, C.; Gobeaux, F.; Vigier, S. Liquid crystalline properties of type I collagen: Perspectives in tissue morphogenesis. Comptes Rendus Chim. 2008, 11, 245-252. [CrossRef]

109. Lydon, J. Microtubules: Nature's smartest mesogens-A liquid crystal model for cell division. Liq. Cryst. Today 2006, 15, 1-10. [CrossRef]

110. Bouligand, Y. Geometry and topology of cell membranes. In Geometry in Condensed Matter Physics; Sadoc, J.F., Ed.; World Scientific: Singapore, 1990; pp. 193-231.

111. Kulkarni, C.V. Lipid crystallization: From self-assembly to hierarchical and biological ordering. Nanoscale 2012, 4, 5779-5791. [CrossRef]

112. Livolant, F.; Levelut, A.M.; Doucet, J.; Benoit, J.P. The highly concentrated liquid crystalline phase of DNA is columnar hexagonal. Nature 1989, 339, 724-726. [CrossRef]

113. Leforestie, A.; Bertin, A.; Dubochet, J.; Richter, K.; Sartori Blanc, N.; Livolant, F. Expression of chirality in columnar hexagonal phases of DNA and nucleosomes. Comptes Rendus Chim. 2008, 11, 229-244. [CrossRef]

114. Leal, C.; Ewert, K.K.; Bouxsein, N.F.; Shirazi, R.S.; Lic, Y.; Safinya, C.R. Stacking of short DNA induces the gyroid cubic-to inverted hexagonal phase transition in lipid-DNA complexes. Soft Matter 2013, 9, 795-804. [CrossRef]

115. Zanchetta, G. Spontaneous self-assembly of nucleic acids: Liquid crystal condensation of complementary sequences in mixtures of DNA and RNA oligomers. Liq. Cryst. Today 2009, 18, 40-49. [CrossRef]

116. Mahadevi, S.A.; Sastry, G.N. Cooperativity in Noncovalent Interactions. Chem. Rev. 2016, 116, $2775-2825$. [CrossRef] [PubMed]

117. Tschierske, C. Microsegregation: From Basic Concepts to Complexity in Liquid Crystal Self-Assembly. Isr. J. Chem. 2012, 52, 935-959. [CrossRef]

118. Rest, C.; Kandanelli, R.; Fernandez, G. Strategies to create hierarchical self-assembled structures via cooperative non-covalent interactions. Chem. Soc. Rev. 2015, 44, 2543-2572. [CrossRef]

119. Takezoe, H. Spontaneous Achiral Symmetry Breaking in Liquid Crystalline Phases. Top. Curr. Chem. 2012, 318, 303-330. [CrossRef] [PubMed]

120. Chen, C.; Kieffer, R.; Ebert, H.; Prehm, M.; Zhang, R.-B.; Zeng, X.; Liu, F.; Ungar, G.; Tschierske, C. Chirality Induction through Nano-Phase Separation: Alternating Network Gyroid Phase by Thermotropic Self-Assembly of X-Shaped Bolapolyphiles. Angew. Chem. Int. Ed. 2020, 59, 2725-2729. [CrossRef] [PubMed]

121. Zeng, X.; Poppe, S.; Lehmann, A.; Prehm, M.; Chen, C.; Liu, F.; Lu, H.; Ungar, G.; Tschierske, C. A Self-assembled Bicontinuous Cubic Phase with Single Diamond Network. Angew. Chem. Int. Ed. 2019, 131,7453-7457. [CrossRef] 
122. Poppe, S.; Cheng, X.; Chen, C.; Zeng, X.; Zhang, R.-B.; Liu, F.; Ungar, G.; Tschierske, C. Liquid Organic Frameworks: The Single-Network "Plumber's Nightmare" Bicontinuous Cubic Liquid Crystal. J. Am. Chem. Soc. 2020, 142, 3296-3300. [CrossRef]

123. Zeng, X.B.; Ungar, G. Spontaneously chiral cubic liquid crystal: Three interpenetrating networks with a twist. J. Mater. Chem. C 2020, 8, 5389-5398. [CrossRef]

124. Kauffman, S. At Home in the Universe; Oxford University Press: Oxford, UK, 1995.

125. Malthete, J.; Nguyen, H.T.; Destrade, C. Phasmids and polycatenar mesogens. Liq. Cryst. 1993, 13, $171-187$. [CrossRef]

126. Nguyen, H.T.; Destrade, C.; Malthete, J. Phasmids and Polycatenar Mesogens. Adv. Mater. 1997, 9, $375-388$. [CrossRef]

127. Bruce, D.W. Calamitics, Cubics, and Columnars. Liquid-Crystalline Complexes of Silver (I). Acc. Chem. Res. 2000, 33, 831-840. [CrossRef] [PubMed]

128. Reppe, T.; Dressel, C.; Poppe, S.; Tschierske, C. Controlling spontaneous mirror symmetry breaking in cubic liquid crystalline phases by the cycloaliphatic ring size. Chem. Commun. 2020, 56, 711-714. [CrossRef] [PubMed]

129. Dressel, C.; Reppe, T.; Poppe, S.; Prehm, M.; Lu, H.; Zeng, X.; Ungar, G.; Tschierske, C. Helical networks of $\pi$-conjugated rods-A robust design concept for bicontinuous cubic liquid crystalline phases with achiral Ia3d and chiral I23 lattice. Adv. Funct. Mater. 2020, submitted.

130. Reppe, T.; Poppe, S.; Cai, X.; Cao, Y.; Liu, F.; Tschierske, C. Spontaneous mirror symmetry breaking in benzil-based soft crystalline, cubic liquid crystalline and isotropic liquid phases. Chem. Sci. 2020, 11, 5902-5908. [CrossRef]

131. Wolska, J.M.; Wilk, J.; Pociecha, D.; Mieczkowski, J.; Gorecka, E. Optically Active Cubic Liquid Crystalline Phase Made of Achiral Polycatenar Stilbene Derivatives. Chem. Eur. J. 2017, 23, 6853-6857. [CrossRef]

132. Kutsumizu, S.; Yamada, Y.; Sugimoto, T.; Yamada, N.; Udagawa, T.; Miwa, Y. Systematic exploitation of thermotropic bicontinuous cubic phase families from 1,2-bis(aryloyl)hydrazine-based molecules. Phys. Chem. Chem. Phys. 2018, 20, 7953-7961. [CrossRef]

133. Kutsumizu, S.; Miisako, S.; Miwa, Y.; Kitagawa, M.; Yamamura, Y.; Saito, K. Mirror symmetry breaking by mixing of equimolar amounts of two gyroid phase-forming achiral molecules. Phys. Chem. Chem. Phys. 2016, 18, 17341-17344. [CrossRef]

134. Pescitelli, G.; Di Bari, L.; Berova, N. Application of electronic circular dichroism in the study of supramolecular systems. Chem. Soc. Rev. 2014, 43, 5211-5233. [CrossRef]

135. Gottarelli, G.; Lena, S.; Masiero, S.; Pieraccini, S.; Spada, G.P. The Use of Circular Dichroism Spectroscopy for Studying the Chiral Molecular Self-Assembly: An Overview. Chirality 2008, 20, 471-485. [CrossRef]

136. Jouvelet, B.; Isare, B.; Bouteiller, L.; von der Schoot, P. Direct probing of the free-energy penalty for helix reversal and chiral mismatches in chiral supramolecular polymers. Langmuir 2014, 30, 4570-4575. [CrossRef]

137. Lu, H.; Zeng, X.; Ungar, G.; Dressel, C.; Tschierske, C. The Solution of the Puzzle of Smectic-Q: The Phase Structure and the Origin of Spontaneous Chirality. Angew. Chem. Int. Ed. 2018, 57, 2835-2840. [CrossRef] [PubMed]

138. Brand, H.R.; Pleiner, H. Cubic and tetragonal liquid crystal phases composed of non-chiral molecules: Chirality and macroscopic properties. Eur. Phys. J. E 2019, 42, 142. [CrossRef] [PubMed]

139. Kajitani, T.; Kohmoto, S.; Yamamoto, M.; Kishikawa, K. Spontaneous Chiral Induction in a Cubic Phase. Chem. Mater. 2005, 17, 3812-3819. [CrossRef]

140. Quack, M. How important is parity violation for molecular and biomolecular chirality? Angew. Chem. Int. Ed. 2002, 41, 4618-4630. [CrossRef]

141. Chandrasekhar, S. Molecular homochirality and the parity-violating energy difference. A critique with new proposals. Chirality 2008, 20, 84-95. [CrossRef]

142. Ha, A.; Cohen, I.; Zhao, X.L.; Lee, M.; Kivelson, D. Supercooled Liquids and Polyamorphism. J. Phys. Chem. 1996, 100, 1-4. [CrossRef]

143. Anisimov, M.A.; Duška, M.; Caupin, F.; Amrhein, L.E.; Rosenbaum, A.; Sadus, R.J. Thermodynamics of Fluid Polyamorphism. Phys. Rev. X 2018, 8, 011004. [CrossRef]

144. Goodby, J.W.; Dunmur, D.A.; Collings, J.P. Lattice melting at the clearing point in frustrated Systems. Liq. Cryst. 1995, 19, 703-709. [CrossRef] 
145. de las Heras, D.; Tavares, J.M.; Telo da Gama, M.M. Phase diagrams of binary mixtures of patchy colloids with distinct numbers of patches: The network fluid regime. Soft Matter 2011, 7, 5615-5626. [CrossRef]

146. Zhuang, Y.; Charbonneau, P. Recent Advances in the Theory and Simulation of Model Colloidal Microphase Formers. J. Phys. Chem. B 2016, 120, 7775-7782. [CrossRef]

147. Henrich, O.; Stratford, K.; Cates, M.E.; Marenduzzo, D. Structure of Blue Phase III of Cholesteric Liquid Crystals. Phys. Rev. Lett. 2011, 106, 107801. [CrossRef]

148. Brand, H.R.; Pleiner, H. On the influence of a network on optically isotropic fluid phases with tetrahedral/octupolar order. Eur. Phys. J. E 2017, 40, 34. [CrossRef] [PubMed]

149. Damer, B.; Deamer, D. The Hot Spring Hypothesis for an Origin of Life. Astrobiology 2020, 20, 429-452. [CrossRef] [PubMed]

150. Camprubí, E.; de Leeuw, J.W.; House, C.H.; Raulin, F.; Russell, M.J.; Spang, A.; Tirumalai, M.R.; Westall, F. The Emergence of Life. Space Sci. Rev. 2019, 215, 56. [CrossRef]

151. Toxvaerd, S. The role of the peptides at the origin of life. J. Theor. Biol. 2017, 429, 164-169. [CrossRef]

152. Gilbert, W. The RNA world. Nature 1986, 319, 618. [CrossRef]

153. Pressman, A.; Blanco, C.; Chen, I.A. The RNA World as a Model System to Study the Origin of Life. Curr. Biol. 2015, 25, R953-R963. [CrossRef]

154. Sutherland, J.D. The Origin of Life-Out of the Blue Angew. Chem. Int. Ed. 2016, 55, 104-121. [CrossRef]

155. Cafferty, B.J.; Fialho, D.M.; Hud., N.V. Searching for Possible Ancestors of RNA: The Self-Assembly Hypothesis for the Origin of Proto-RNA. In Prebiotic Chemistry and Chemical Evolution of Nucleic Acids. Nucleic Acids and Molecular Biology; Menor-Salván, C., Nicholson, A.W., Eds.; Springer-Nature: Cham, Switzerland, 2018; Volume 35.

156. Krishnamurthy, R. On the Emergence of RNA. Isr. J. Chem. 2015, 55, 837-850. [CrossRef]

157. Xu, J.; Tsanakopoulou, M.; Magnani, C.R.; Szabla, R.; Šponer, J.E.; Šponer, J.; Góra, R.W.; Sutherland, J.D. A prebiotically plausible synthesis of pyrimidine $\beta$-ribonucleosides and their phosphate derivatives involving photoanomerization. Nat. Chem. 2017, 9, 303-309. [CrossRef]

158. Nama, I.; Nama, H.G.; Zareb, R.N. Abiotic synthesis of purine and pyrimidine ribonucleosides in aqueous microdroplets. Proc. Natl. Acad. Sci. USA 2018, 115, 36-40. [CrossRef] [PubMed]

159. Becker, S.; Feldmann, J.; Wiedemann, S.; Okamura, H.; Schneider, C.; Iwan, K.; Crisp, A.; Rossa, M.; Amatov, T.; Carell, T. Unified prebiotically plausible synthesis of pyrimidine and purine RNA ribonucleotides. Science 2019, 366, 76-82. [CrossRef] [PubMed]

160. Hunter, C.A.; Sanders, J.K.M. The Nature of Interactions. J. Am. Chem. Soc. 1990, 112, 5525-5534. [CrossRef]

161. Martinez, C.R.; Iverson, B.L. Rethinking the term "pi-stacking". Chem. Sci. 2012, 3, 2191-2201. [CrossRef]

162. Krueger, A.T.; Kool, E.T. Model systems for understanding DNA base pairing. Curr. Opin. Chem. Biol. 2007, 11, 588-594. [CrossRef] [PubMed]

163. Joyce, G.F.; Schwartz, A.W.; Miller, S.L.; Orgel, L.E. The case for an ancestral genetic system involving simple analogues of the nucleotides. Proc. Natl. Acad. Sci. USA 1987, 84, 4398-4402. [CrossRef]

164. Chen, Y.; Ma, W. The origin of biological homochirality along with the origin of life. PLoS Comput. Biol. 2020, 16, e1007592. [CrossRef]

165. Sandars, P.G.H. A toy model for the generation of homochirality during polymerization. Orig. Life Evol. Biosph. 2003, 33, 575-587. [CrossRef]

166. Wattis, J.A.D.; Coveney, P.V. Symmetry-breaking in chiral polymerisation. Orig. Life Evol. Biosph. 2005, 35, 243-273. [CrossRef]

167. Jain, V.; Cheon, K.-S.; Tang, K.; Jha, S.; Green, M.M. Chiral Cooperativity in Helical Polymers. Isr. J. Chem. 2011, 51, 1067-1074. [CrossRef]

168. Baumgarten, J.L. Ferrochirality: A simple theoretical model of interacting, dynamically invertible, helical polymers, $2^{\dagger}$. Molecular field approach: Supports and the details. Macromol. Theory Simul. 1995, 4, 1-43. [CrossRef]

169. Stich, M.; Hochberg, D. Mechanically Induced Homochirality in Nucleated Enantioselective Polymerization, Celia Blanco. J. Phys. Chem. B 2017, 121, 942-955. [CrossRef] 
170. Buchs, J.; Vogel, L.; Janietz, D.; Prehm, M.; Tschierske, C. Chirality Synchronization of Hydrogen-Bonded Complexes of Achiral N-Heterocycles. Angew. Chem. Int. Ed. 2017, 56, 280-284. [CrossRef]

171. Karunakaran, S.C.; Cafferty, B.J.; Weigert-MuÇoz, A.; Schuster, G.B.; Hud, N.V. Spontaneous Symmetry Breaking in the Formation of Supramolecular Polymers: Implications for the Origin of Biological Homochirality. Angew. Chem. Int. Ed. 2019, 58, 1453-1457. [CrossRef] 